\title{
The Importance of Near-Surface Winter Precipitation Processes in Complex Alpine Terrain
}

\author{
FRANZISKA GERBER
}

Laboratory of Cryospheric Sciences, School of Architecture and Civil Engineering, École Polytechnique Fédérale de Lausanne, Lausanne, and WSL Institute for Snow and Avalanche Research SLF, Davos, Switzerland

\section{REBECCA MOTT}

Institute of Meteorology and Climate Research-Atmospheric Environmental Research (IMK-IFU), Karlsruhe Institute of Technology-Campus Alpin, Garmisch-Partenkirchen, Germany, and WSL Institute for Snow and Avalanche Research SLF, Davos, Switzerland

\section{MICHAEL LEHNING}

Laboratory of Cryospheric Sciences, School of Architecture and Civil Engineering, École Polytechnique Fédérale de Lausanne, Lausanne, and WSL Institute for Snow and Avalanche Research SLF, Davos, Switzerland

(Manuscript received 21 March 2018, in final form 24 October 2018)

\begin{abstract}
In this study, near-surface snow and graupel dynamics from formation to deposition are analyzed using WRF in a large-eddy configuration. The results reveal that a horizontal grid spacing of $\leq 50 \mathrm{~m}$ is required to resolve local orographic precipitation enhancement, leeside flow separation, and thereby preferential deposition. At this resolution, precipitation patterns across mountain ridges show a high temporal and spatial variability. Simulated and observed event-mean snow precipitation across three mountain ridges in the upper Dischma valley (Davos, Switzerland) for two precipitation events show distinct patterns, which are in agreement with theoretical concepts, such as small-scale orographic precipitation enhancement or preferential deposition. We found for our case study that overall terrain-flow-precipitation interactions increase snow accumulation on the leeward side of mountain ridges by approximately $26 \%-28 \%$ with respect to snow accumulation on the windward side of the ridge. Cloud dynamics and mean advection may locally increase precipitation on the leeward side of the ridge by up to about $20 \%$ with respect to event-mean precipitation across a mountain ridge. Analogously, near-surface particle-flow interactions, that is, preferential deposition, may locally enhance leeward snow precipitation on the order of $10 \%$. We further found that overall effect and relative importance of terrain-flow-precipitation interactions are strongly dependent on atmospheric humidity and stability. Weak dynamic stability is important for graupel production, which is an essential component of solid winter precipitation. A comparison to smoothed measurements of snow depth change reveals a certain agreement with simulated precipitation across mountain ridges.
\end{abstract}

\section{Introduction}

Snow distribution in complex alpine terrain is determined by many different processes. At a mountain-range scale, large-scale orographic precipitation enhancement is dominant, causing enhanced snow accumulation on the upstream side of a mountain range due to forced lifting and condensation (e.g., Stoelinga et al. 2013). Decreasing precipitation occurs downstream, where air masses are sinking and drying. However, at smaller scales, additional processes, such as local orographic precipitation

Corresponding author: Franziska Gerber, gerberf@slf.ch enhancement and particle-flow interactions (i.e., the influence of the local flow field on the pathways of snow particles and the particle distribution in the air), become important due to the interaction of the local flow field with topography (e.g., Zängl 2007; Lehning et al. 2008; Mott et al. 2014; Grazioli et al. 2015). Since the highly variable mountain snow cover is a result of these and additional (e.g., avalanches, snow saltation) processes, assessment or prediction of snow water resources or avalanche danger can only be achieved if these processes are quantitatively understood.

The flow over mountain ridges may introduce low-level clouds due to lifting condensation (e.g., Banta 1990). 
Particles falling through such low-level clouds may strongly grow at the expense of cloud droplets by depositional growth or form rimed particles or graupel by collision (Stoelinga et al. 2013). This process is also known as the seeder-feeder mechanism (Bergeron 1965). Because of small-scale orographic precipitation enhancement, without taking into account precipitation advection, a precipitation peak is expected over the mountain ridge (Mott et al. 2014). However, particleflow interactions additionally act on the precipitation distribution close to the ground, especially for flows over steep topography (Lehning et al. 2008; Mott et al. 2014). A main effect is mean advection, which leads to a downstream shift of peak precipitation, but organized and turbulent eddies close to the surface will further modify fall velocities and therefore deposition. For example, close-ridge updrafts on the windward side of the mountain ridge are expected to reduce the terminal fall velocity of precipitation. Hence, snow accumulation on the windward side of the mountain ridge can be reduced and precipitation particles are transported over the ridge. On the leeward side of the ridge, where precipitation faces flow separation, snow will be preferentially deposited. Increased deposition may also be found through flow blocking at the foot of a hill or mountain or in depressions with reduced flow speeds (e.g., Carruthers and Hunt 1990; Lehning and Mott 2016). These effects have been introduced as preferential deposition by Lehning et al. (2008). In contrast to predepositional precipitation processes, which shape the snow distribution already during snowfall in and below the clouds, postdepositional processes may additionally alter snow accumulation patterns by redistribution of snow by wind (Vionnet et al. 2017) and avalanches (e.g., Bernhardt et al. 2012; Sommer et al. 2015).

There are different approaches to investigate winter precipitation over complex topography. Simple, though based on physical principles, the linear theory model (Smith and Barstad 2004) represents certain aspects of orographic precipitation over complex terrain (Roth et al. 2018). The linear theory model, as well as numerical weather prediction models, is usually used at horizontal grid spacings of $\geq 1 \mathrm{~km}$ for precipitation studies (e.g., Richard et al. 2007; Rasmussen et al. 2011; Pontoppidan et al. 2017). Higher resolution comes at infeasible computational cost for operational applications. For mountain-range-scale orographic precipitation enhancement, only weak improvement of precipitation representation was found when increasing the horizontal grid spacing from 3 to $1 \mathrm{~km}$ (Pontoppidan et al. 2017). The small-scale variability of snow accumulation has been addressed with atmospheric numerical models, based on semi-idealized conditions (real topography and idealized or partially idealized boundary conditions) either coupled to or used as input for a snow model (e.g., Mott et al. 2014; Vionnet et al. 2017). Based on this approach, different studies found evidence for preferential deposition in numerical simulations, which could be verified by means of snow depth measurements (e.g., Mott and Lehning 2010; Mott et al. 2010, 2014). However, effects of different atmospheric conditions and terrain on preferential deposition are still under debate (e.g., Mott et al. 2010, 2014; Gerber et al. 2017; Vionnet et al. 2017; Wang and Huang 2017; Comola et al. 2018, manuscript submitted to J. Geophys. Res. Atmos., hereafter CGSPL). Mott and Lehning (2010) could reproduce snow accumulation patterns that agree fairly well with the original definition of preferential deposition, and their simulations show good correspondence to field measurements. Recent studies show that preferential deposition strongly depends on the local flow field and atmospheric stability (e.g., Wang and Huang 2017; CGSPL). Wang and Huang (2017) report a shift of peak snow precipitation from the windward toward the leeward side of the ridge for increasing advection strength. Recently, CGSPL confirmed that deposition patterns strongly depend on the strength of advection, while precipitation patterns are qualitatively preserved for varying slope angles, based on idealized large-eddy simulations (LES). Furthermore, they addressed particle inertia, which is disregarded by many models. Their results showed that snow accumulation patterns resulting from simulations with inertialess particles are similar to patterns simulated for inertial dendritic particles. However, simulations based on inertialess particles do not properly represent snow accumulation patterns as expected for rounded particles with inertia. While it is well known that postdepositional particle-flow interactions have a strong impact on the small-scale snow distribution in complex terrain (e.g., Vionnet et al. 2017), the relative importance of clouddynamical effects and predepositional particle-flow interactions needs further quantification (Mott et al. 2014; Vionnet et al. 2017).

Regional simulations are usually limited to a horizontal grid spacing of $\geq 1 \mathrm{~km}$ as discussed above. A new comparison of Weather Research and Forecasting (WRF) Model simulations driven by Consortium for Small-Scale Modeling (COSMO-2) analysis (COSMOWRF) to high-resolution radar measurements indicates that wintertime precipitation patterns over complex terrain are not fully captured by model simulations even at a horizontal grid spacing of $450 \mathrm{~m}$, while some additional small-scale variability is resolved at a horizontal grid spacing of $50 \mathrm{~m}$ (Gerber et al. 2018a). Furthermore, Gerber et al. (2018a) found differences in precipitation 
patterns between a horizontal plane at the elevation of an operational weather radar on a mountain peak and the ground level, indicating the presence of near-surface processes.

In this study, we address the question of at which resolution the model starts to resolve mountain-ridge-scale precipitation processes. Therefore, we analyze the sensitivity of mountain-ridge-scale precipitation processes to the model resolution (section 3a). Based on very highresolution simulations (50-m horizontal grid spacing), we then estimate the relative importance of predepositional precipitation processes. To this end, we first present and discuss topographically induced precipitation processes in the COSMO-WRF setup (sections $3 b$ and $3 c$ ). Subsequently, we compare modeled precipitation patterns with photogrammetrically determined snow accumulation measurements (section 3d). Finally, we estimate the importance of predepositional precipitation processes on the snow accumulation distribution in COSMO-WRF simulations (section 3e). Conclusions and an outlook wrap up this study in section 4 .

\section{Data and methods}

\section{a. COSMO-WRF simulations}

For this study, simulations are performed with the nonhydrostatic and fully compressible WRF Model (Skamarock et al. 2008). The simulations are run with initial and boundary conditions from the COSMO-2 analysis by MeteoSwiss. The simulation setup corresponds to the one described in Gerber et al. (2018a). All simulations have four one-way nested domains (d01d04) with horizontal grid spacings of $1350,450,150$, and $50 \mathrm{~m}$, respectively (Fig. 1). The four simulation domains have 40, 40, 60, and 90 vertical levels, respectively, with the model top at $150 \mathrm{hPa}$. Analysis of near-surface processes are based on domain d04 (50-m horizontal grid spacing), which covers the upper Dischma valley (Davos, Switzerland). To address the resolution sensitivity of processes, precipitation patterns are compared in the model output at the different horizontal grid spacings of 50,150 , and $450 \mathrm{~m}$. The coarsest horizontal grid spacing of $1350 \mathrm{~m}$ is not used in the analysis, as even at a horizontal grid spacing of $450 \mathrm{~m}$, mountain-ridge- to mountain-valley-scale precipitation processes may not be resolved (section 3a).

Using this simulation setup, two precipitation events on 31 January 2016 and 5 March 2016 are simulated. The simulations are run for $24 \mathrm{~h}$ with a spinup time of 43,19 , 7 , and $1 \mathrm{~h}$ for the domains d01-d04, respectively. The 31 January 2016 and 5 March 2016 dates are chosen because these were two significant precipitation events within the time period, for which photogrammetrically determined airborne snow depth measurements are available (section 2e). Additionally, simulations for these two dates showed better performance compared to simulations for another precipitation event on 4 February 2016 (Gerber et al. 2018a). For the variability analysis with respect to radar estimates, the simulations were chosen to cover full calendar days corresponding to the preprocessing of radar measurements.

Boundary layer processes in the parent domain (d01) are parameterized by the Yonsei University planetary boundary layer (YSU PBL) scheme (Hong et al. 2006), while all the nested domains are run in LES mode. For subgrid-scale turbulence, the 1.5-order turbulent kinetic energy parameterization is used (Skamarock et al. 2008).

Microphysical processes are parameterized by the Morrison two-moment parameterization (Morrison et al. 2005, 2009). Land surface processes are parameterized by the Noah land surface model with multiparameterization options (Noah-MP; Niu et al. 2011; Yang et al. 2011) and linked to the atmosphere by the MM5 Monin-Obukhov surface layer parameterization (Paulson 1970; Dyer and Hicks 1970; Webb 1970; Zhang and Anthes 1982; Beljaars 1995). Terrain smoothing (four smoothing cycles using the 1-2-1 smoothing option of the WRF preprocessing system; Gerber et al. 2018a) is applied to keep all slope angles in domain d04 below $45^{\circ}$. This smoothing is necessary to avoid pressure gradient errors (De Wekker 2002). The same number of smoothing cycles is applied for all four nested domains to keep topography consistent across domain boundaries. To take missing topography and missing roughness elements into account, the snow surface roughness length is increased to $0.2 \mathrm{~m}$ (Gerber et al. 2018a).

The simulations have been validated against two meteorological stations in domain d04. Gerber et al. (2018a) could show that the simulations perform well, especially in terms of wind direction, but with clearly overestimated wind speeds for some time periods and expositions, especially for the precipitation event on 31 January 2016. Additionally, precipitation tends to be overestimated with respect to radar estimates. Further information about the simulation setup and the validation can be found in Gerber and Sharma (2018) and Gerber et al. (2018a).

Two sensitivity simulations are run to address the impact of different simulation resolutions but eliminate the effect of additional smoothing. The first simulation includes domains $\mathrm{d} 01$ and $\mathrm{d} 02$ and has maximum slope angles of $45^{\circ}$ in domain $\mathrm{d} 02$. The second simulation has three domains ( $\mathrm{d} 01, \mathrm{~d} 02$, and $\mathrm{d} 03)$ and restricts slope angles to $<45^{\circ}$ in domain d03. Keeping all slope angles below $45^{\circ}$ in domain $\mathrm{d} 02$ (horizontal grid spacing of 

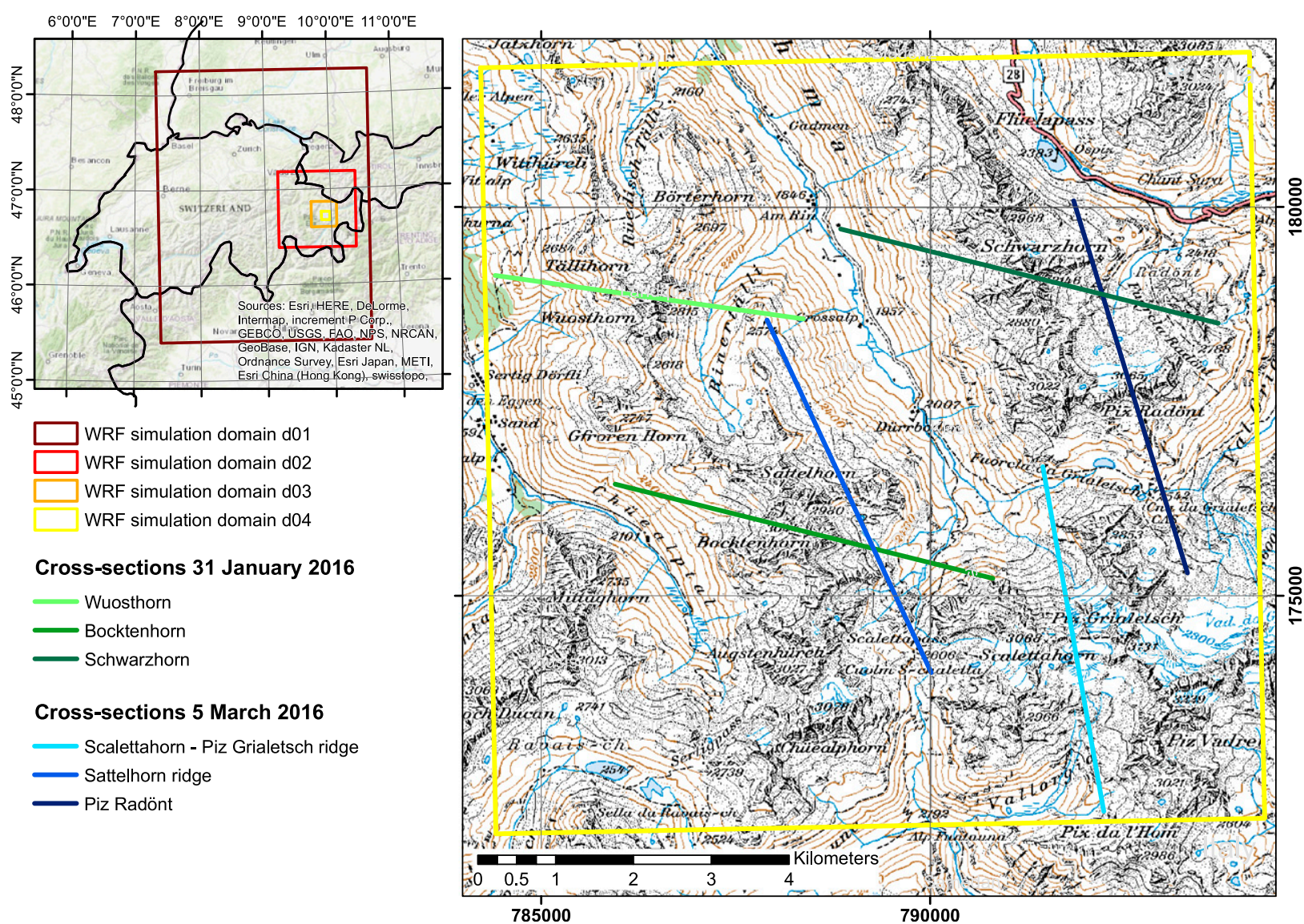

FIG. 1. (left) Overview of the study area over the eastern part of Switzerland and surrounding countries. The simulation domains d01d04 (dark red to yellow) with 1350-, 450-, 150-, and 50-m horizontal grid spacing, respectively, show the simulation setup. Domain d04 covers the upper Dischma valley (Davos, Switzerland). Cross sections analyzed for the two precipitation events on 31 Jan 2016 (green) and 5 Mar 2016 (blue) are approximately centered over the respective mountain peak or ridge. (right) Base map: pixmaps (c) 2018 swisstopo (5704 000000$)$

$450 \mathrm{~m}$ ) requires one smoothing cycle. Three smoothing cycles are needed to keep all slope angles below $45^{\circ}$ in domain d03 (horizontal grid spacing of $150 \mathrm{~m}$ ). The specified number of smoothing cycles is applied to all nested domains of the respective simulation.

\section{b. Precipitation events}

To analyze close-ground terrain-flow-precipitation interactions (i.e., the influence of terrain-induced flow field variations including turbulence on the precipitation formation and distribution), we investigate two precipitation events on 31 January 2016 and 5 March 2016. On 31 January 2016 a westerly flow induced by the Azores high and a low pressure system over Scandinavia dominated the weather over central Europe. Temperatures were about $-3^{\circ} \mathrm{C}$ at $2500 \mathrm{~m}$ above mean sea level (MSL). Temperatures on 5 March 2016 were slightly lower, with about $-7^{\circ} \mathrm{C}$ at $2500 \mathrm{~m}$ MSL. The general flow direction over the eastern part of Switzerland was from the south due to a large depression area over central Europe. The events further differ in their relative humidity $(\mathrm{RH})$. While $\mathrm{RH}$ is high over the whole domain $\mathrm{d} 04$ for the precipitation event on 31 January 2016, saturation is only reached in the vicinity of the mountain peaks on 5 March 2016, and an RH gradient is observed with higher humidity toward the southern boundary of the domain. The dry static stability of the atmosphere in the area of the different mountain ridges is weakly stable for both precipitation events, as expected for winter conditions over snow-covered terrain. For the precipitation event on 31 January 2016, precipitation over $24 \mathrm{~h}$ (from 0000 UTC 31 January 2016 until 0000 UTC 1 February 2016) is analyzed (hereafter January event). For the precipitation event on 5 March 2016, only $10 \mathrm{~h}$ are analyzed between 0700 and 1700 UTC covering the precipitation period during southerly advection (hereafter March event). For the sensitivity study, only the January event is analyzed. 
TABLE 1. Characteristics of the wind conditions and distance from the ridge for peak snow precipitation. Distances are given separately for the processes of mean advection and orographic precipitation enhancement (precipitation distribution at $\sim 95 \mathrm{~m}$ AGL) and nearsurface preferential deposition (precipitation distribution in the lowest $\sim 95 \mathrm{~m} \mathrm{AGL}$ ) in domain d04 with a horizontal grid spacing of $50 \mathrm{~m}$. Values show averages over the respective precipitation event (section 2b). See section $2 c$ and Fig. 2 for further explanation. "Adv. max." is the distance of the first precipitation maximum on the leeward side of the mountain ridge at $~ 95 \mathrm{~m}$ AGL (Fig. 2). "Pref. dep. max." is the distance of relative precipitation maxima closest to the ridge on the windward side of the ridge (negative values) and on the leeward side of the ridge (positive values) of the precipitation distribution in the lowest $\sim 95 \mathrm{~m}$ AGL.

\begin{tabular}{llccrr}
\hline \hline & & Wind dir. $\left(^{\circ}\right)$ & Wind speed $\left(\mathrm{m} \mathrm{s}^{-1}\right)$ & Adv. max. $(\mathrm{m})$ & Pref. dep. max. $(\mathrm{m})$ \\
\hline \multirow{2}{*}{ January event } & Wuosthorn & 278 & 13.7 & 600 & 250 \\
& Schwarzhorn & 284 & 19.6 & 1100 & $-50 / 300$ \\
\multirow{3}{*}{ March event } & Bocktenhorn & 284 & 15.7 & 650 & 0 \\
& Sattelhorn ridge & 155 & 11.2 & 250 & 100 \\
& Piz Radönt & 163 & 14.1 & 500 & $0 / 200$ \\
\hline
\end{tabular}

\section{c. Study area and cross sections across mountain ridges}

This study is part of the Dischma experiment (DISCHMEX), which was launched to investigate the effect of atmospheric processes on snow accumulation (Gerber et al. 2017, 2018a) and ablation (Mott et al. 2017; Schlögl et al. 2018) in alpine terrain. The upper Dischma valley is located within the eastern Swiss Alps to the south of Davos (Fig. 1).

The effect of the flow field on precipitation processes and final snow deposition is analyzed based on cross sections across six mountain peaks or ridges. The mountain peaks and ridges as well as the direction of the cross sections were chosen depending on the event and the main wind direction in domain d04 (Fig. 1). For the January event, with a main wind direction from northwest to west, cross sections across the Wuosthorn, Schwarzhorn, and Bocktenhorn are analyzed. For the March event cross sections across the Sattelhorn ridge, the ridge between Scalettahorn and Piz Grialetsch, and Piz Radönt are chosen.

The direction of each cross section is determined by the mean wind [wind speed $\left(\mathrm{m} \mathrm{s}^{-1}\right)$ and wind direction $\left({ }^{\circ}\right)$ in Table 1] for the respective precipitation event over a square with side lengths of $500 \mathrm{~m}$ centered over the simulation grid point closest to the main mountain peak or ridge crest, taking into account the lowest $\sim 350 \mathrm{~m}$ above ground level (AGL; 11 lowest model levels) in domain $\mathrm{d} 04$. The cross sections have a length of $5 \mathrm{~km}$ and are approximately centered over the main mountain peak or ridge. Two exceptions are the cross sections across Wuosthorn, which has a length of $4 \mathrm{~km}$, and the cross section across the ridge between Scalettahorn and Piz Grialetsch with a cross-section length of $4.5 \mathrm{~km}$, restricted by the extent of domain d04. The same cross sections are used for the sensitivity analysis of different model resolutions.

\section{d. Quantification of preferential deposition and cloud-dynamical processes}

To retrieve an estimate of near-surface preferential deposition and cloud-dynamical processes, we separate the two processes based on a simple approach. Previous studies showed that preferential deposition mainly acts at the lowest $\sim 100 \mathrm{~m}$ of the atmosphere, while clouddynamical processes are dominant above this height (Mott et al. 2014). In agreement with these results, our model simulations show only a weak precipitation formation and growth or even a reduction (due to sublimation) below $\sim 93-410 \mathrm{~m}$ AGL (depending on the cross section) in the cross section and event-mean precipitation rate (Tables $\mathrm{A} 1$ and $\mathrm{A} 2$ in appendix A). Above $\sim 93-410 \mathrm{~m}$ AGL, the cross-section and eventmean precipitation rate per elevation $\left(\mathrm{mm} \mathrm{h}^{-1} \mathrm{~m}^{-1}\right)$ strongly increases (by up to $50 \%-60 \%$ ) or changes from a precipitation reduction to a precipitation increase with respect to the level below. A weak increase of precipitation with increasing model level within the lowest part of the atmosphere (below the seventh model level, $\sim 95 \mathrm{~m}$ AGL, depending on the location) over the main ridge, supports the assumption that precipitation formation and growth (by cloud-dynamical processes) below the lowest $\sim 95 \mathrm{~m}$ AGL are of minor importance (Figs. 2c, A1g-i, A2g-i).

Therefore, we assume that the difference between precipitation distribution at $\sim 3 \mathrm{~m}$ AGL (first model level) and $\sim 95 \mathrm{~m}$ AGL (seventh model level) is dominated by near-surface preferential deposition. Precipitation patterns above $\sim 95 \mathrm{~m}$ AGL are assumed to be dominated by the combined effect of cloud dynamics and mean advection (red line in Figs. 2, A1, A2).

Slightly different elevations are chosen for the comparison of different model resolutions, due to differences in the number of (eta) levels in our simulations. Cloud-dynamical processes and mean advection are 

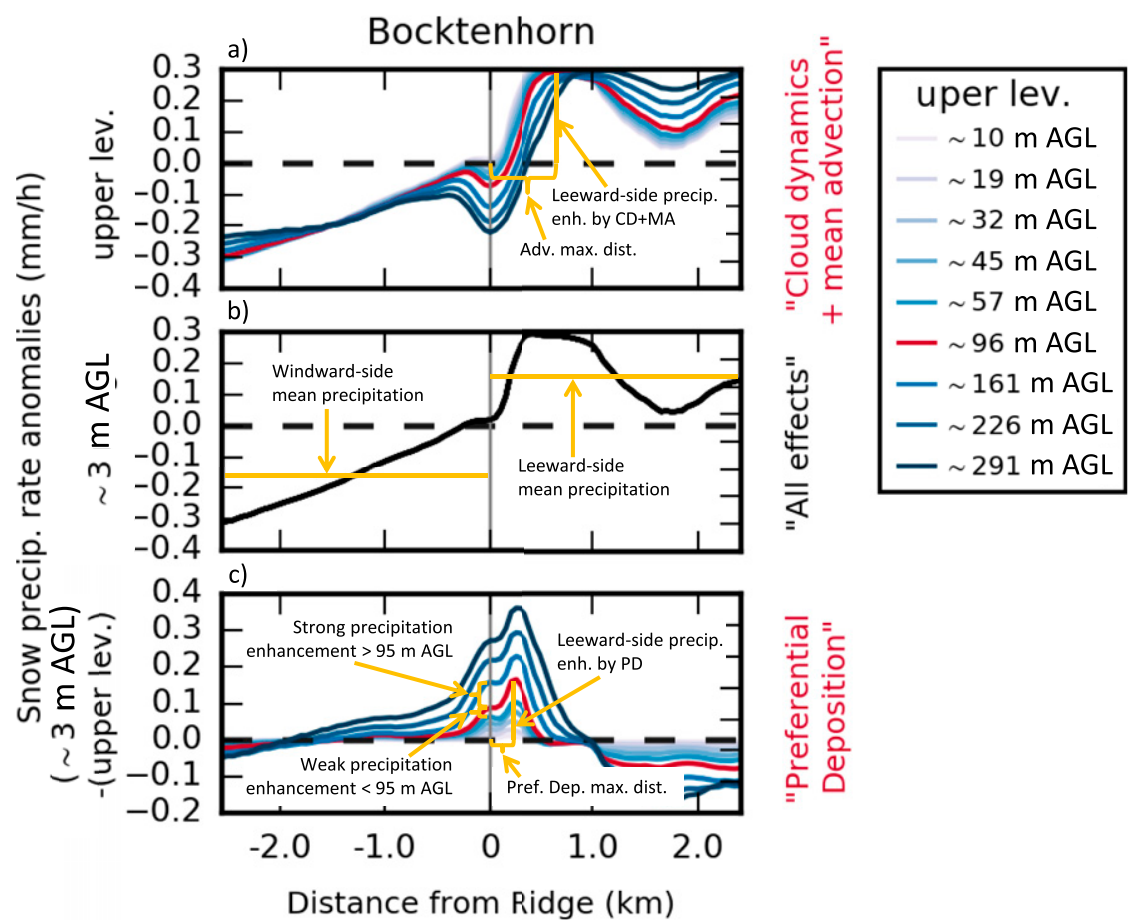

FIG. 2. Illustration of the snow precipitation processes and precipitation patterns at different levels above ground level for the Bocktenhorn (January event, 50-m horizontal grid spacing). (a) Event-mean snow precipitation rate anomalies at nine different model levels (upper lev.) between $\sim 10$ and $\sim 291 \mathrm{~m}$ AGL. (b) Event-mean snow precipitation rate anomalies at the lowest model level $\sim 3 \mathrm{~m}$ AGL. (c) Snow precipitation distribution due to processes between the lowest model level $\sim 3 \mathrm{~m}$ AGL [shown in (b)] and the upper level [shown in (a)]. Precipitation enhancement (precip. enh.) due to processes in the lowest $\sim 96 \mathrm{~m}$ AGL is shown by the red line, showing the effect of cloud dynamics (CD) and mean advection (MA) in (a) and near-surface preferential deposition (PD) in (c). Additional terms and abbreviations are explained in section $2 \mathrm{~d}$ and Table 1 .

estimated at $\sim 80 \mathrm{~m}$ AGL for domains $\mathrm{d} 02$ and $\mathrm{d} 03$ (second model level) and are compared to $\sim 95 \mathrm{~m}$ AGL in domain $\mathrm{d} 04$. The lowest model level in domains $\mathrm{d} 02$ and $\mathrm{d} 03$ is at $\sim 20 \mathrm{~m}$ AGL. Therefore, we use the third model level ( $\sim 20 \mathrm{~m}$ AGL) of domain d04 when addressing differences between model resolutions.

This technique has limitations. The separation of processes is only approximatively exclusive and small precipitation changes in the lowest $\sim 95 \mathrm{~m}$ AGL show that cloud-dynamical and microphysical processes are still active in the lowest $\sim 95 \mathrm{~m}$ AGL. However, in the cross-section and event-mean precipitation the effect of precipitation generation or reduction below this level is weak, indicating the dominance of preferential deposition within the lowest atmospheric levels.

The local importance of cloud dynamics and mean advection (near-surface preferential deposition) is estimated as the positive precipitation anomaly at the first local maximum downstream of the main mountain ridge at $\sim 95 \mathrm{~m}$ AGL (within the lowest $\sim 95 \mathrm{~m}$ AGL) with respect to the cross-section and event-mean precipitation rate at $\sim 95 \mathrm{~m}$ AGL ( $\sim 3 \mathrm{~m}$ AGL; Figs. 2a,c). The effect of near-surface preferential deposition is only estimated for cross sections, for which sublimation in the lowest $\sim 95 \mathrm{~m}$ AGL does not induce a snow precipitation decrease $>0.02 \mathrm{~mm} \mathrm{~h}^{-1}$ (i.e., excluding Sattelhorn ridge and Piz Radönt for the March event). The cumulated effect of cloud dynamics, mean advection, and near-surface preferential deposition is estimated as the event-mean precipitation on the leeward side versus the event-mean precipitation on the windward side of the mountain ridge at $\sim 3 \mathrm{~m}$ AGL (Fig. $2 \mathrm{~b}$, windwardand leeward-side mean precipitation).

\section{e. Photogrammetrically determined snow depth distribution}

Snow depth maps with a resolution of $2 \mathrm{~m}$, retrieved from airborne photogrammetry, are available for the Dischma valley for two days in winter 2015/16. Flights have been performed on 26 January 2016 and 9 March 2016, covering the Dischma valley and the Wannengrat area. Absolute snow depth is calculated by the difference 
of the winter flights and a snow-free flight in September 2013 and is corrected for buildings, vegetation $(>1 \mathrm{~m})$, outliers, and pixels, which are obviously snow-free on the pictures (Bühler et al. 2015). To evaluate snow accumulation patterns, the difference between the winter snow depth maps on 9 March 2016 and on 26 January 2016 is calculated.

The uncertainty of the snow depth maps is about $\pm 30 \mathrm{~cm}$ (Bühler et al. 2015). However, both flights were performed during slightly cloudy conditions, which lead to weak image matching, resulting in a high number of interpolated snow depth values in certain areas. This introduces additional uncertainty. Furthermore, about 1.5 months passed between the two measurements, implying that several snowfall events, postdepositional snow redistribution, and snow settling shape the observed snow accumulation patterns.

Based on snow depth change and corresponding wind direction measurements of five automatic weather stations in the surroundings of the Dischma valley, about $67.6 \%$ of the summed snow accumulation between 26 January and 9 March 2016 happened during northeasterly, northerly, northwesterly, and westerly advection and $32.4 \%$ during easterly, southeasterly, southerly, and southwesterly advection. To compare measured snow accumulation patterns to modeled snow precipitation patterns, solid precipitation simulated for the January and March event (section 2b) is weighted by these percentages. This implies the assumption that the precipitation distribution is similar for different precipitation events with the same main wind direction. Individual storms likely result in different precipitation patterns (e.g., due to different atmospheric conditions). However, the peak-of-winter snow distribution was found to be consistent, with few major storms shaping the peak of winter snow distribution (Schirmer et al. 2011). The two analyzed precipitation events were two out of three major snow precipitation events between 26 January and 9 March 2016, and thus likely representative for the precipitation distribution during this period.

The snow depth measurements and simulated snow precipitation are compared along four transects within the simulation domain d04 (Fig. 6): two in northwesterly to southeasterly direction and two in southerly to northerly direction. They are chosen such that areas of interpolated snow depths (i.e., areas with weak image matching) are best possibly avoided. Snow depth measurements are smoothed using a 500-m and a $100-\mathrm{m}$ moving average filter to make large-scale trends visible.

\section{Results and discussion}

Results are presented and discussed as follows: first, precipitation patterns are analyzed with respect to different model resolutions (section 3a). Subsequently, precipitation patterns developing either due to the combined effect of cloud dynamics and mean advection (section 3b) or near-surface preferential deposition (section 3c) are discussed. A comparison of modeling results with spatial snow depth measurements is provided in section 3d. Finally, we estimate the contribution of the different precipitation processes to snow accumulation patterns in the COSMO-WRF model (section 3e).

\section{a. Effects of model resolution on the representation of snow precipitation processes}

Model resolution has as strong effect on the representation of topography and thus, especially in complex terrain, on the depths and heights of valleys and mountain peaks respectively. This affects terrain-flow interactions, which have a strong influence on precipitation formation and distribution (e.g., Lehning et al. 2008; Mott et al. 2014). Therefore, we illustrate the importance of very high-resolution simulations, to address mountain-ridge- to mountain-valley-scale precipitation distribution in complex alpine terrain.

In our COSMO-WRF simulations with a horizontal grid spacing of $450 \mathrm{~m}$, no clear sign of local orographic precipitation enhancement or near-surface preferential deposition is found (Figs. 3a,g). Mountain ridges are quite flat for a horizontal grid spacing of $450 \mathrm{~m}$ (Fig. 3k). Consequently, updrafts are weak going along with a low cloud-droplet concentration (i.e., weak low-level cloud formation) and a weak precipitation production over shallow mountain peaks, which is in agreement with findings in Gerber et al. (2018a).

Up- and downdrafts become more pronounced for simulations with a horizontal grid spacing of $150 \mathrm{~m}$ (Fig. 31). This results in slightly enhanced precipitation on the leeward side of the mountain ridge (Figs. 3b,e) and indicates that the combined effect of local cloud dynamics and mean advection starts to be resolved. Slightly enhanced precipitation deposition over the mountain peak is further visible, likely due to reduced updrafts over the mountain ridge (Figs. 3h,l) preventing the transport of snow over the ridge. Leeside flow separation is not resolved, which leads to a quite homogeneous precipitation distribution in the lowest $\sim 95 \mathrm{~m}$ AGL.

For simulations with a horizontal grid spacing of $50 \mathrm{~m}$, updrafts are even stronger than for simulations with a horizontal grid spacing of $150 \mathrm{~m}$ (Fig. $3 \mathrm{~m}$ ). Downdrafts on the leeward side of the mountain ridge become weaker and leeside flow separation or even a leeside eddy start to be resolved. Small-scale flow features such as leeside eddies are in agreement with flow fields observed during field measurements and in LESs with a 

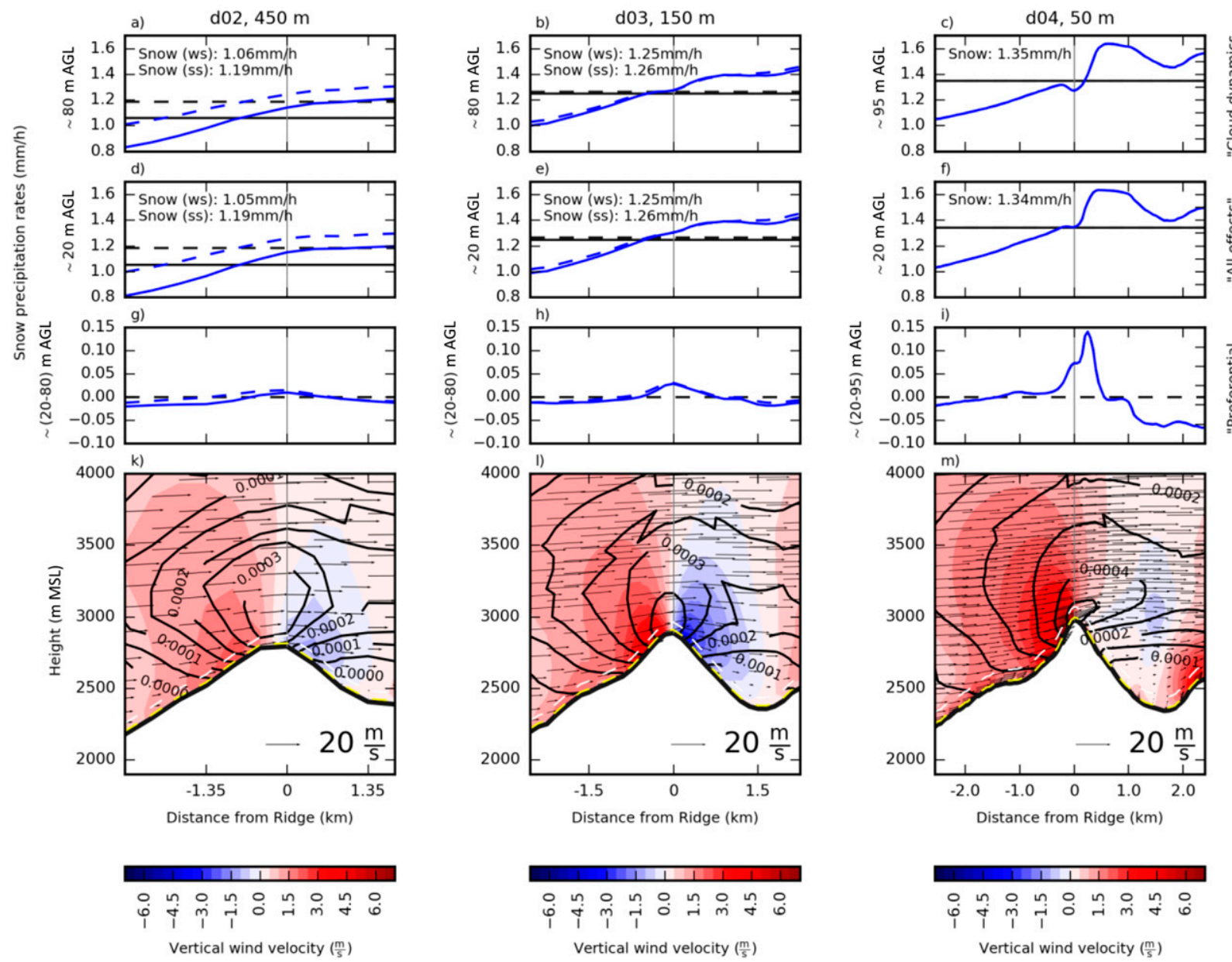

FIG. 3. Precipitation rates and wind fields for the Bocktenhorn cross section (January event, Fig. 1). Event-mean snow precipitation rates at (a)-(c) $\sim 80 \mathrm{~m} \mathrm{AGL}$ or $\sim 95 \mathrm{~m} \mathrm{AGL}$ and (d)-(f) $\sim 20 \mathrm{~m}$ AGL. (g)-(i) Difference of the event-mean snow precipitation rates between $\sim 20 \mathrm{~m}$ AGL and $\sim 80 \mathrm{~m}$ or $\sim 95 \mathrm{~m}$ AGL. For simulations with 450 - and 150-m horizontal grid spacing, event-mean snow precipitation rates are given for weaker smoothing (solid blue line; maximum slope angles of $45^{\circ}$ in d04) and strong smoothing (dashed blue line; maximum slope angles of $45^{\circ}$ in $\mathrm{d} 02$ and d03, respectively). Solid (dashed) black lines in (a)-(f) mark the cross-section and eventmean snow precipitation rate for weak (strong) terrain smoothing, which are given in the upper-left corner as "Snow (ws)" and "Snow (ss)," respectively. (k)-(m) Topography (m MSL), vertical wind velocities (shading), plane wind (arrows), and cloud droplet mixing ratio (black contours). The yellow (white) dashed lines mark the $\sim 80 \mathrm{~m}$ AGL or $\sim 95 \mathrm{~m}$ AGL ( $\sim 20 \mathrm{~m} \mathrm{AGL).}$

horizontal grid spacing of $25 \mathrm{~m}$ (e.g., Gerber et al. 2017). They may strongly affect snow precipitation patterns. Flow separation on the leeward side of the mountain ridge results in peak precipitation in the area of weak wind speeds on the leeward side of the mountain ridge. This peak precipitation due to terrain-flow interactions in the lowest $\sim 95 \mathrm{~m}$ AGL is in good agreement with preferential deposition. Enhanced condensation and precipitation production are associated with larger elevation differences in topography on the windward side of the mountain ridge at a horizontal grid spacing of $50 \mathrm{~m}$ compared to a horizontal grid spacing of $150 \mathrm{~m}$.
Mean advection leads to a downstream shift of the precipitation peak toward the leeward side of the ridge (Mott et al. 2014; section 3b). Similar precipitation patterns and flow fields emerge over the other three mountain ridges for the two precipitation events (not shown).

A sensitivity study is performed to address the effect of stronger versus weaker smoothing of the model topography (section 2a). Restricting maximum slope angles in domain $\mathrm{d} 04$ to $45^{\circ}$ yields maximum slope angles of $39.8^{\circ}$ and $35.2^{\circ}$ in domains $\mathrm{d} 03$ and $\mathrm{d} 02$, respectively (strong smoothing). They are compared to simulations 
with weaker smoothing, that is, maximum slope angles of $45^{\circ}$ in domains d03 and d02 (Fig. 3). When regarding the whole simulation domain $\mathrm{d} 02$, an upstream shift of precipitation is observed for weaker smoothing. This confirms the findings by Gerber et al. (2018a) that too-small slope angles in the northwestern part of domain $\mathrm{d} 02$ are responsible for weak precipitation in this area. In the Dischma valley, we observe the opposite behavior (less precipitation for weaker smoothing), which is a consequence of the upstream "rain out." However, weaker smoothing (i.e., more pronounced valleys and ridges) compared to stronger smoothing reveals a stronger elevation gradient of precipitation, which is in agreement with enhanced condensation due to larger elevation differences. The variability of precipitation across the investigated mountain ridges does not strongly change for different smoothing strengths.

Overall, these simulation results reveal that precipitation patterns across mountain ridges strongly depend on the grid resolution in COSMO-WRF simulations (Fig. 3). The spatial variability of precipitation patterns increases with increasing model resolution, and a horizontal grid spacing of $50 \mathrm{~m}$ is required to resolve local clouddynamical effects and near-surface preferential deposition. This is in agreement with Mott and Lehning (2010), who found that effects of preferential deposition on the leeward slope may be represented at a horizontal grid spacing of $50 \mathrm{~m}$. However, to fairly represent deposition on windward slopes and postdepositional patterns, even higher model resolutions and a coupling to an alpine surface processes model (e.g., Alpine3D; Lehning et al. 2008) would be required.

\section{b. Cloud-dynamical effects and mean advection}

To determine main features of cloud dynamics and advection, we analyze precipitation patterns at $\sim 95 \mathrm{~m}$ AGL in domain d04 (50-m horizontal grid spacing; section 2d). Cloud-dynamical effects are expected to lead to precipitation enhancement over the mountain ridge, for example, by the seeder-feeder mechanism (e.g., Mott et al. 2014). Low-level clouds are likely to produce graupel by accretion of cloud droplets on falling ice or snow particles (e.g., Grazioli et al. 2015). However, depositional growth may also enhance snow precipitation and may be facilitated by small-scale flow features (Stoelinga et al. 2013). The January and March events show strong differences with respect to graupel production. Therefore, we separately analyze snow and graupel precipitation patterns.

Snow precipitation patterns across mountain ridges show a strong temporal variability (Figs. $4 \mathrm{a}-\mathrm{c}, 5 \mathrm{a}-\mathrm{c}$ ). This indicates that snow precipitation and its interaction with the local flow field are very dynamic and sensitive to the upstream flow conditions. However, some distinct patterns are observed in the event-mean snow precipitation rates across the investigated mountain ridges (Figs. 4, 5).

Mean snow precipitation patterns across four mountain ridges show a peak in precipitation a few hundred meters downstream of the main mountain ridge (Figs. 4d-f, 5f). This represents the combined effect of small-scale orographic precipitation enhancement and mean advection. In the WRF Model, snow may grow or form by deposition, collection of cloud droplets, or autoconversion of ice (i.e., when ice reaches a certain size by vapor diffusion growth; Morrison et al. 2005). For Wuosthorn, Schwarzhorn, and Bocktenhorn (Figs. 4d-f), local snow precipitation production at higher elevations is in agreement with the presence of a high cloud-droplet concentration (i.e., depositional precipitation growth or precipitation growth by riming) over and downstream of the mountain ridge (Figs. 4n,p). Snow precipitation produced over the mountain ridge may be transported downstream, or transport of condensates (cloud droplets) may enhance snow precipitation growth downstream of the main ridge.

For the Sattelhorn ridge, peak snow precipitation is very close to the ridge (Fig. 5d). This may be due to weaker advection of hydrometeors due to lower wind speeds (Table 1) or efficient downstream sublimation. No snow precipitation peak emerges for Piz Radönt for the March event. The March event shows southerly advection. The relatively dry air is a sign that at the large scale the Dischma valley is downstream of main precipitation for a southerly event and strongly influenced by a downstream drying of the atmosphere. This is in agreement with its location in the interior of the alpine mountain range (Fig. 1). Downstream drying is confirmed by precipitation patterns observed on a larger scale, both in the model and in radar precipitation estimates (Gerber et al. 2018a). Additionally, a general sinking of air masses is observed at $4000 \mathrm{~m}$ MSL for the March event (Figs. 5n-p), while air masses are lifted on a large-scale for the January event (Figs. $4 n-p)$. Piz Radönt is the northernmost of the three investigated mountain ridges for the March event and may hence be located in too dry air to face local snow precipitation enhancement.

Strong differences between the two precipitation events are apparent for graupel. The January event does not show any significant graupel formation $(<1 \%$ of mean solid precipitation across the three investigated cross sections, not shown). For the March event, on the other hand, graupel formation makes up $5 \%-10 \%$ of mean solid precipitation across the three investigated cross sections (Fig. 5). Graupel production in the model is 

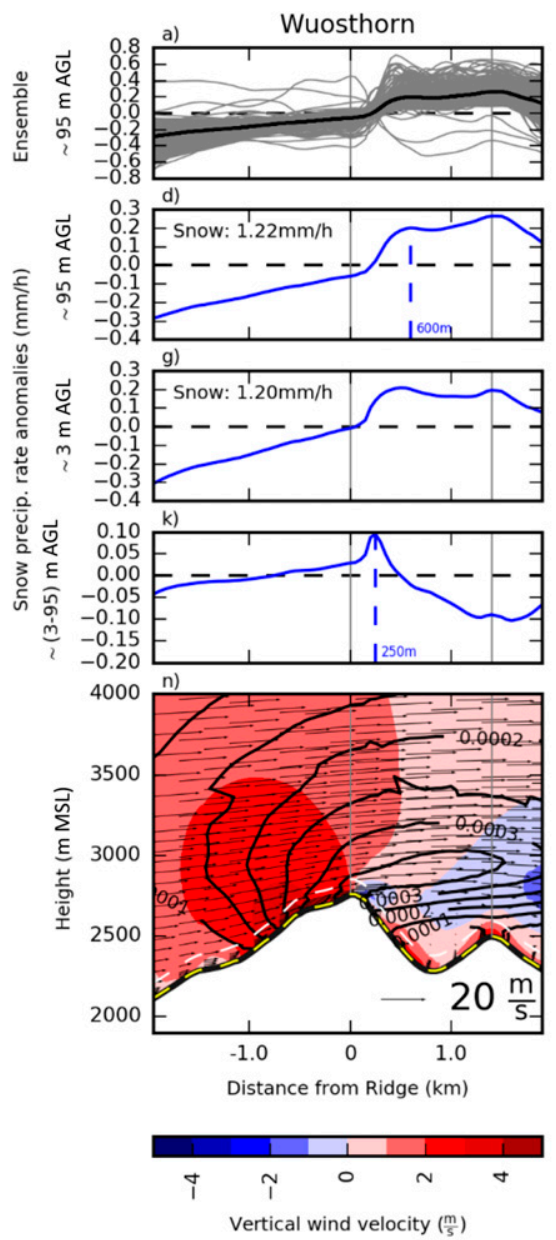
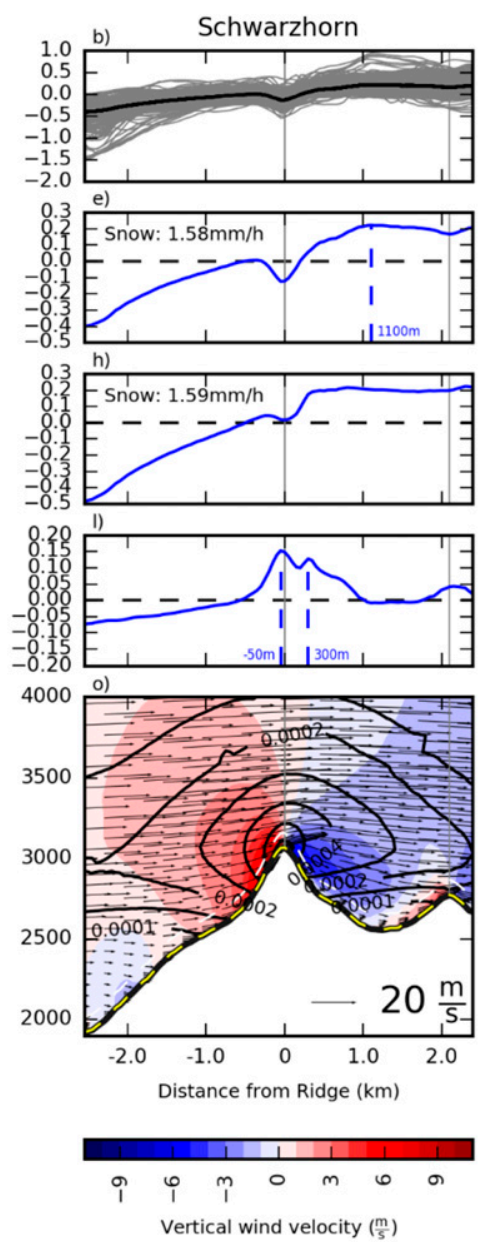
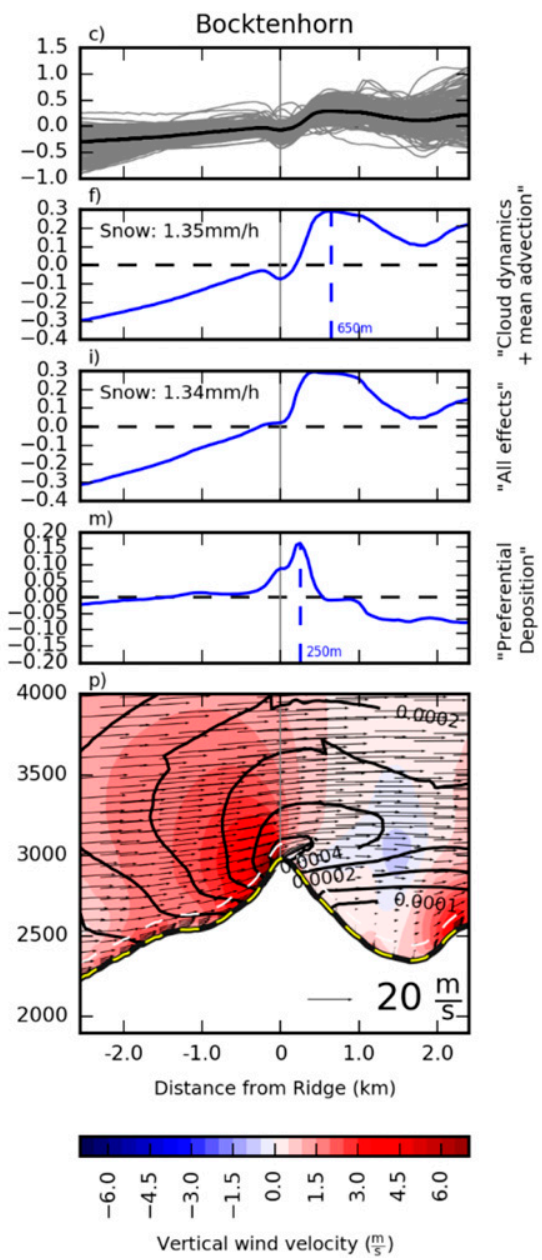

FIG. 4. Precipitation rates and wind fields for the January event (50-m horizontal grid spacing, Fig. 1). (a)-(c) 288 individual 5-min snow precipitation rate anomalies (gray) and 24-h mean snow precipitation rate anomaly (black). Event-mean snow precipitation rate anomalies at (d)-(f) $\sim 95 \mathrm{~m} \mathrm{AGL}$ and (g)-(i) $\sim 3 \mathrm{~m}$ AGL (solid blue lines). Cross-section and event-mean precipitation rates are given in the upper-left corner. $(\mathrm{k})-(\mathrm{m})$ Difference of snow precipitation rates between $\sim 3$ and $\sim 95 \mathrm{~m}$ AGL (solid blue lines). Dashed blue lines and distances in (d)-(f) and (k)-(m) mark precipitation peaks due to cloud dynamics and mean advection (Adv. max.) and near-surface preferential deposition (Pref. dep. max.), respectively (see Table 1 and Fig. 2 for additional explanations). (n)-(p) Topography (m MSL), vertical wind velocities (shading), plane wind (arrows), and cloud droplet mixing ratio (black contours). The white (yellow) dashed lines mark the $\sim 95 \mathrm{~m}$ AGL $(\sim 3 \mathrm{~m}$ AGL). Note different scales.

based on (i) conversion of ice or snow to graupel by riming with cloud droplets, (ii) collision of rain with snow or ice, or (iii) freezing of rain (Reisner et al. 1998; Morrison et al. 2005). The two winter precipitation events addressed in this study produce a negligible amount of liquid precipitation in the upper Dischma valley, and therefore processes including rain are irrelevant. For both events snow and cloud droplets do not coexist widely. However, there is a higher amount of ice available for the March event compared to the January event, which may be a reason for stronger graupel production. Additionally, smaller Richardson numbers up to higher atmospheric levels indicate stronger vertical shear of the horizontal wind and a lower dynamic stability of the atmosphere for the March event compared to the January event (appendix B). This is in agreement with Grazioli et al. (2015), who found wind shear to be an important component of precipitation enhancement and the formation of rimed particles. Turbulent updrafts due to wind shear may lead to a continuous feeding of supercooled liquid water (i.e., cloud droplets) and ice crystals to the layer above the shear layer, where precipitation growth may take place consequently (Hogan et al. 2002). Once present, graupel may grow at the expense of cloud droplets or by deposition (Reisner et al. 1998). Another source of graupel may be the transport of graupel into the domain by mean advection, which is, however, not very likely due to their high fallout rates. 

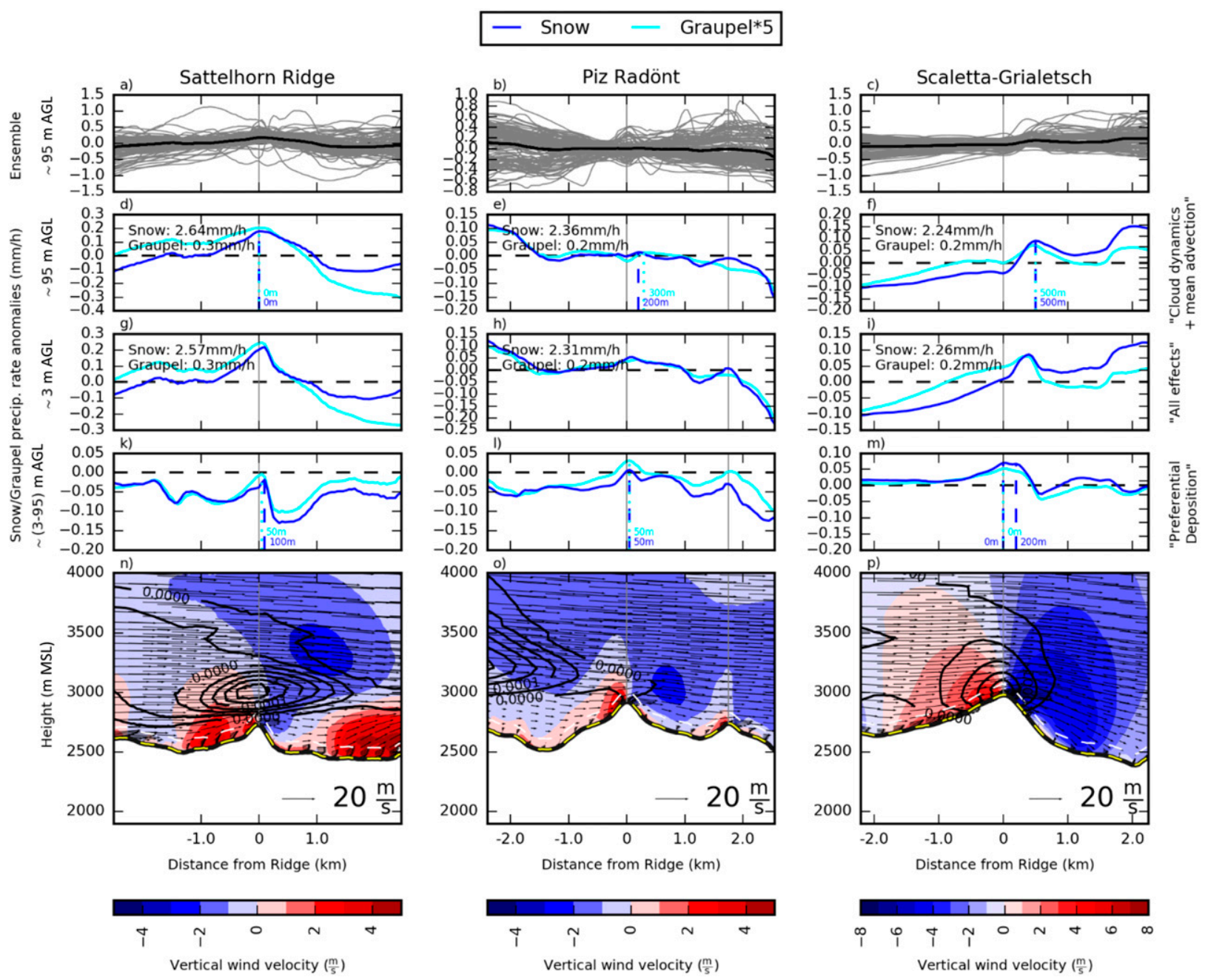

FIG. 5. Precipitation rates and wind fields for the March event (50-m horizontal grid spacing, Fig. 1). (a)-(c) 120 individual 5-min snow precipitation rate anomalies (gray) and 10-h mean snow precipitation rate anomaly (black). Mean precipitation rate anomalies at (d)-(f) $\sim 95 \mathrm{~m} \mathrm{AGL}$ and (g)-(i) $\sim 3 \mathrm{~m}$ AGL. Cross-section and event-mean of snow or graupel precipitation are given in the upper left corner. (k)-(m) Difference of precipitation rates between $\sim 3$ and $\sim 95 \mathrm{~m}$ AGL. Snow precipitation is given by solid blue lines. Graupel precipitation (solid cyan lines) is exaggerated by a factor of 5. Dashed blue (cyan) lines and distances in (d)-(f) and (k)-(m) mark peak snow (graupel) precipitation due to cloud dynamics and mean advection (Adv. max.), and near-surface preferential deposition (Pref. dep. max.), respectively (Table 1 and Fig. 2). (n)-(p) Topography (m MSL), vertical wind velocities (shading), plane wind (arrows), and cloud droplet mixing ratio (black contours). The white (yellow) dashed lines mark the $\sim 95 \mathrm{~m}$ AGL ( $\sim 3 \mathrm{~m}$ AGL). Note different scales.

Overall, for the March event, snow and graupel precipitation show similar precipitation patterns with enhanced precipitation a few hundred meters downstream of the mountain ridge. Differences in precipitation distribution across different mountain ridges for the two investigated precipitation events are attributed to different atmospheric conditions (i.e., relative humidity). When regarding the combined effect of cloud-dynamical processes and particle-flow interactions throughout the atmosphere (i.e., precipitation distribution $\sim 3 \mathrm{~m}$ AGL; Figs. $4 \mathrm{~g}-\mathrm{i}, 5 \mathrm{~g}-\mathrm{i})$ precipitation patterns across mountain ridges are similar to precipitation patterns $\sim 95 \mathrm{~m}$ AGL.
The patterns agree well with the expected asymmetric precipitation distribution across a mountain ridge with peak precipitation downstream of the main ridge (Mott et al. 2014).

\section{c. Near-surface particle-flow interactions}

For Wuosthorn and Bocktenhorn (January event) and for Sattelhorn ridge (March event), a snow precipitation peak on the leeward side of the mountain ridge is observed due to processes in the lowest $\sim 95 \mathrm{~m}$ AGL (Figs. $4 \mathrm{k}, \mathrm{m}$ and $5 \mathrm{k}$; section $2 \mathrm{~d}$ ). Assuming that precipitation patterns in the lowest $\sim 95 \mathrm{~m}$ AGL are dominated by particle-flow 
interactions, the simulated precipitation patterns may be regarded as near-surface preferential deposition. Peak precipitation as observed is in agreement with the concept of preferential deposition (Lehning et al. 2008). The snow distribution patterns represent the expected precipitation distribution for a precipitation transport over the mountain ridge and peak accumulation on the leeward side of the mountain ridge, where the flow field shows weak downdrafts or even a leeside eddy. However, reduced snow precipitation due to reduced fall speeds on the windward side of the mountain ridge is not represented in the model. Although the lowest $\sim 95 \mathrm{~m}$ AGL are assumed to be dominated by particle-flow interactions, weak local snow precipitation growth may still take place and lead to snow precipitation enhancement in the vicinity of the mountain ridge, where the air is saturated. This might be a reason for increasing snow precipitation on the windward side close to the mountain ridge. For some cross sections (Wuosthorn, Bocktenhorn, Sattelhorn ridge, and Piz Radönt), a slight decrease in mean snow precipitation is observed in the lowest $\sim 95 \mathrm{~m}$ AGL (appendix A), which is a sign for sublimation of precipitation. This effect is stronger for the March event compared to the January event due to drier air masses (section 2b).

For Schwarzhorn (Fig. 4l) and the ridge between Scalettahorn and Piz Grialetsch (Fig. 5m), a double peak of snow precipitation is observed with the main snow precipitation peak at the mountain ridge and a second snow precipitation peak downstream of the mountain ridge. The second snow precipitation peak is likely a sign of preferential deposition as reported above. The snow precipitation peak over or slightly upstream of the mountain ridge may occur in this case but not in the other cases because terrain-induced updrafts are restricted to the windward side of Schwarzhorn and the ridge between Scalettahorn and Piz Grialetsch (Figs. 4o, $5 p$ ), while above the mountain peak vertical wind speeds are almost zero. Thus, precipitation may be deposited over these mountain ridges, while active updrafts prevent enhanced deposition over other ridge tops.

For the March event, graupel precipitation shows similar precipitation patterns as snow precipitation but graupel precipitation peaks show a tendency to be slightly shifted upstream compared to peaks of snow precipitation. The most likely reason for this is that graupel has higher fall speeds and therefore reaches the ground earlier than snow (Zängl 2007).

In a recent study by CGSPL, the particle shape (expressed by particle inertia) has been reported to strongly affect precipitation distribution across an idealized hill. Flow conditions and snow precipitation patterns for the three mountain ridges Wuosthorn and Bocktenhorn (January event) and Sattelhorn (March event) in our (inertialess) simulations are consistent with accumulation patterns for inertialess particles and strong advection in CGSPL, for which they found a precipitation peak on the leeward side of the mountain ridge. Based on CGSPL, this would imply that precipitation patterns in our simulations are representative for dendritic particles. For rounded particles (e.g., graupel) different patterns would, however, be likely. Similar precipitation patterns for mountain ridges with different slope angles confirm the findings by CGSPL that steepness may not be a main factor determining snow precipitation patterns due to particle-flow interactions. Still, differences in snow and graupel precipitation patterns across different mountain ridges confirm that particle shape and inertia have an influence.

Overall, snow and graupel precipitation patterns in the lowest $\sim 95 \mathrm{~m}$ AGL show a precipitation peak at the mountain ridge or slightly downstream for all investigated cross sections. For the March event a much weaker sign of near-surface preferential deposition and a smaller downstream shift of peak precipitation are observed compared to precipitation patterns for the January event. Different patterns are attributed to different atmospheric conditions: the January event has updraft motions close to the surface (except for Schwarzhorn), while for the March event downward vertical motion predominates on the leeward side. Furthermore, the March event is characterized by drying conditions leading to sublimation, while the January event shows a saturated atmosphere.

\section{d. Modeled precipitation patterns versus measured snow depth changes}

Snow depth measurements with a resolution of $2 \mathrm{~m}$ based on airborne photogrammetry (Fig. 6a) show a very high spatial variability of snow accumulation. A high spatial variability of snow accumulation patterns is expected, especially in steep terrain, due to the effect of postdepositional snow redistribution by wind and avalanches (e.g., Sommer et al. 2015).

A comparison of filtered snow accumulation measurements (500- and 100-m moving average, solid and dashed red lines in Figs. 6b-e) to precipitation patterns from COSMO-WRF simulations with a horizontal grid spacing of $50 \mathrm{~m}$ (solid blue lines in Figs. 6b-e) reveals that COSMO-WRF simulations show a lower spatial variability but a stronger enhancement of snow precipitation over the southwestern part of domain $\mathrm{d} 04$. The former confirms that very high-resolution simulations are essential to capture snow accumulation patterns over complex terrain (section 3a). The latter may be an indication that local orographic precipitation enhancement over the highest mountain ridges is 


\begin{tabular}{|c|c|c|c|c|c|}
\hline Simulation domain & Cross sections Soutn-North & Cross section West-East & Terrain & WRF precipitation & Measured snow depth \\
\hline d04 & $\begin{array}{l}-\mathrm{SN} \text { - West } \\
-\mathrm{SN} \text { - East }\end{array}$ & $\begin{array}{l}\text { — WE - North } \\
\text { - WE - South }\end{array}$ & $\begin{array}{ll}\text { - } & \text { Real terrain } \\
\text { WRF terrain }\end{array}$ & $\begin{array}{l}\text { - WRF ground precip. anomalies } \\
\text { - WRF preferential deposition }\end{array}$ & $\begin{array}{l}\text { - Snow depth anomalies }(500 \mathrm{~m} \text { window) } \\
- \text { Snow depth anomalies }(100 \mathrm{~m} \text { window) }\end{array}$ \\
\hline
\end{tabular}

a)

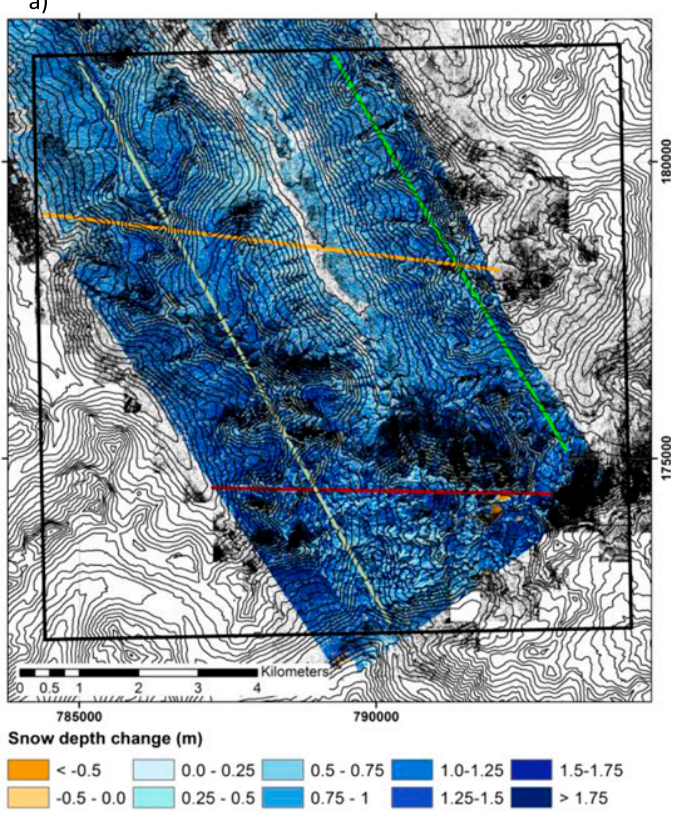

d) SN - West

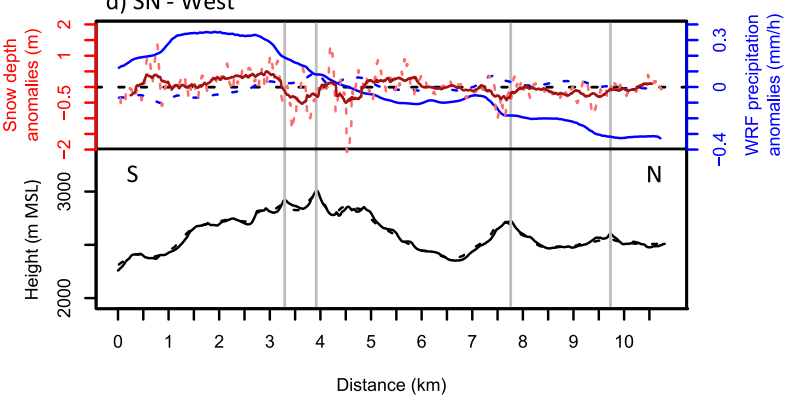

b) WE - North
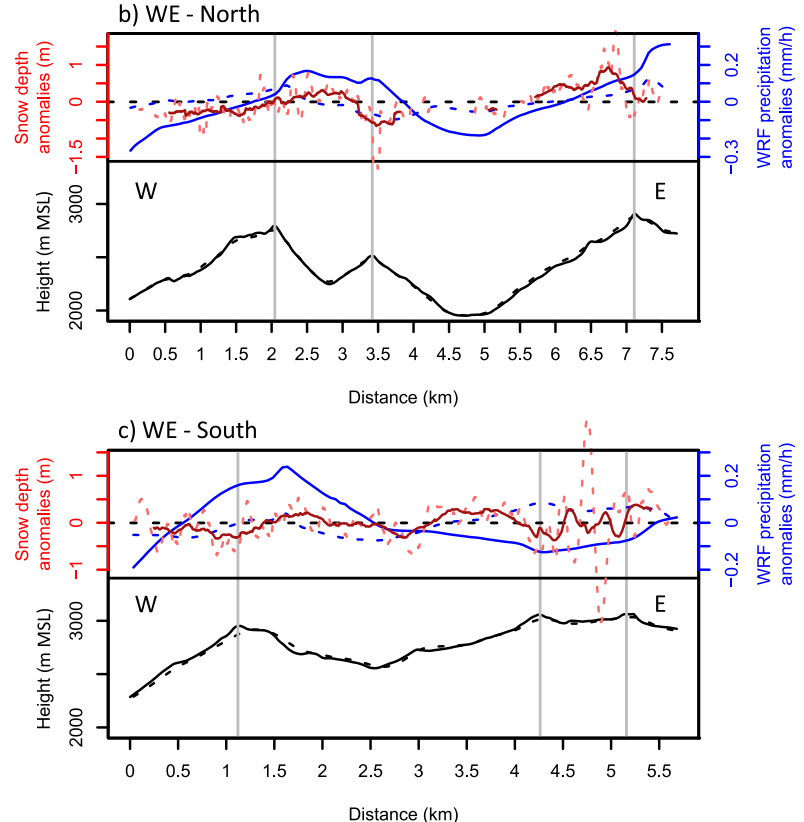

e) SN - East

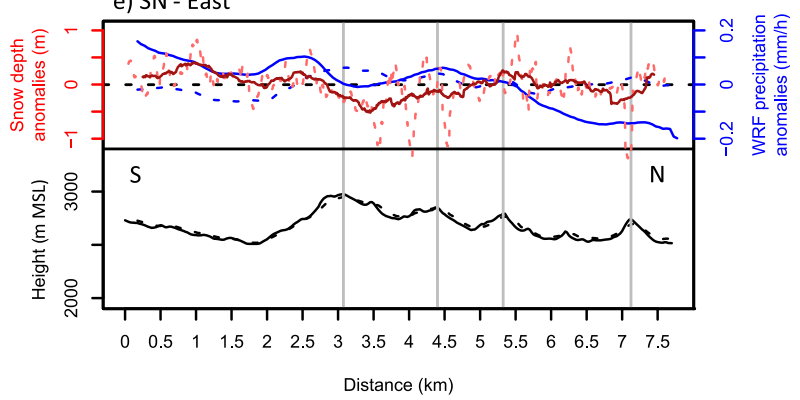

FIG. 6. Cross-sections of COSMO-WRF precipitation patterns (50-m horizontal grid spacing) vs airborne photogrammetric snow depth change measurements with a resolution of $2 \mathrm{~m}$. (a) Snow depth changes (m) in the upper Dischma valley between 26 Jan and 9 Mar 2016. Four transects within domain d04 [black box in (a)] are marked by solid lines in (a): (b) northern and (c) southern transect from west $(\mathrm{W})$ to east $(\mathrm{E})$ and $(\mathrm{d})$ western and (e) eastern transect from south $(\mathrm{S})$ to north $(\mathrm{N})$. Black shadings in (a) show interpolated snow depth estimates (section 2e). COSMO-WRF ground precipitation anomalies $\left(\mathrm{mm} \mathrm{h}^{-1}\right.$; solid blue line) with respect to transect mean precipitation and precipitation difference between $\sim 3$ and $\sim 95 \mathrm{~m}$ AGL (dashed blue line) are compared to measured snow depth patterns ( $\mathrm{m}$; red lines). Measured snow depth is smoothed using a moving average with a window length of $100 \mathrm{~m}$ (dashed red line) and $500 \mathrm{~m}$ (solid red line). Real and modeled topography are shown by black solid and dashed lines, respectively. Contour lines in (a) are based on dhm25 (c) 2018 swisstopo (5704 000 000).

overestimated in the model simulations (Gerber et al. 2018a). This is likely due to an overestimation of precipitation production in the microphysics parameterization, which was originally developed for simulations with a much coarser resolution. On the other hand, a flattening of the snow distribution toward mountain ridges based on snow depth measurements was reported before (Grünewald et al. 2014; Kirchner et al. 2014) and could be a sign for postdepositional snow redistribution at high-elevation sites, which is not represented in the model. Although there are various reasons for disagreement, for two transects local precipitation trends on the order of a few kilometers show a certain agreement with filtered snow accumulation trends (Figs. 6b,e).

In the lowest $\sim 95 \mathrm{~m}$ AGL, particle-flow interactions produce a small-scale snow deposition pattern, which does typically not show maximum deposition at highest elevations (Figs. 6b-e, dashed blue lines). Some snow accumulation peaks based on measurements are in agreement with precipitation peaks due to near-surface processes in the model, which are likely dominated by 
near-surface preferential deposition (section 2d), while others are shifted, likely due to postdepositional snow transport in reality. Overall, it is interesting to note that for two transects (Figs. 6c,d) large-scale precipitation patterns due to near-surface processes in the model show a closer agreement with measured snow accumulation than modeled total snow precipitation distribution. This may be an indication that, at a mountain-ridge scale, near-surface processes are more important for the final snow accumulation distribution than precipitation distribution farther above ground. The fact that postdepositional blowing is driven by similar wind field variations as preferential deposition further helps to understand this interesting observation.

Differences may have manifold reasons from missing postdepositional snow redistribution in the model to measurement uncertainties (section 2e). Furthermore, aspect and slope of the mountain ridges are important parameters, for example, determining snow settling and ablation (e.g., Grünewald et al. 2013; Kirchner et al. 2014). However, the presented comparison reveals that precipitation patterns at a mountain-ridge to mountainvalley scale in COSMO-WRF simulations at a horizontal grid spacing of $50 \mathrm{~m}$ partially represent snow depth measurements based on airborne photogrammetry, supporting the precipitation scaling approach suggested by Vögeli et al. (2016). Precipitation parameterizations with a weak scale dependency and even higher-resolution simulations would be required to further improve the representation of local precipitation patterns in complex terrain. Additionally, a coupling to an alpine surface processes model (e.g., Alpine3D; Lehning et al. 2008) would be beneficial for a refined comparison.

\section{e. Estimation of the relative importance of different processes}

Based on our analysis, we estimate the relative importance of different processes on the snow precipitation distribution across mountain ridges, being aware that the processes may not be fully distinguishable (section 2d). Therefore, we always refer to the levels for which patterns are found, acknowledging that processes we refer to may not be the only ones in action. In this sense, the average values discussed in the following are only an example for the specific case analyzed here (section 2d). At the same time, the values may be quite typical, but we cannot show this.

Small-scale orographic precipitation enhancement and mean advection, which are likely dominant above the lowest $\sim 95 \mathrm{~m}$ AGL, may locally lead to an increase in snow precipitation of up to about $20 \%$ with respect to cross-section and event-mean precipitation (section $2 \mathrm{~d}$ ). The strength of local orographic precipitation enhancement and mean advection shows a strong variability between mountain peaks and precipitation events. The strongest dependency is observed with respect to the precipitation event. While local orographic precipitation enhancement and mean advection increase snow precipitation by $14 \%-22 \%$ for the January event, the enhancement is only responsible for differences by $1 \%-7 \%$ for the March event. The most likely reason for this difference is that the March event goes along with much drier air compared to the January event (section 3b). For strong advection the precipitation peak is not expected over the ridge but shifted a few hundred meters downstream of the main ridge (Figs. 4, 5; section 3b; Mott et al. 2014). Mean advection and peak snow precipitation distance from the ridge show a tendency of an increasing downstream shift of peak snow precipitation with increasing wind speeds (Table 1). However, this trend is only valid when comparing patterns for the same precipitation event.

The effect of particle-flow interactions in the lowest $\sim 95 \mathrm{~m}$ AGL (section 2d) may induce local changes of snow precipitation patterns on the order of $10 \%$ with respect to event-mean snow precipitation across the respective mountain ridge. As for local orographic precipitation enhancement and mean advection, the effect is stronger for the January event, where nearsurface preferential deposition changes snow precipitation patterns by $8 \%-12 \%$. The effect estimated for the ridge between Scalettahorn and Piz Grialetsch accounts for $3 \%$. Sublimation, which should be strengthened on the leeward side of the mountain ridge due to descending air, is again the likely reason for a weaker snow precipitation peak induced by preferential deposition for the March event compared to the January event.

The cumulated effect of orographic precipitation enhancement, mean advection, and near-surface preferential deposition results in asymmetric snow accumulation patterns across mountain ridges (Mott et al. 2014). In our simulations the strength of this asymmetry is strongly dependent on the atmospheric conditions. For the two case studies, we attribute the differences to the humidity of the atmosphere. However, there are likely other factors which determine the snow precipitation distribution across mountain ridges. While we report a weak asymmetryeven reversed for the Sattelhorn ridge and Piz Radöntof a from $-2 \%$ to $6 \%$ enhancement of event-mean snow precipitation on the leeward side of the mountain ridge with respect to event-mean snow precipitation on the windward side of the mountain ridge (section 2d), we can show that for humid conditions (as presented for the January event) terrain-flow-precipitation interactions may increase snow precipitation on the leeward side of the 
TABLE A1. Cross-section and event-mean precipitation rate changes between the given model level and the level below for the January event. The elevation gives the cross-section mean elevation above ground averaged over all three cross sections analyzed for the January event. Snow precipitation rate changes are given in $\mathrm{mm} \mathrm{h}^{-1}$ and $\mathrm{mm} \mathrm{h}^{-1} \mathrm{~m}^{-1}$. Precipitation rate changes in $\mathrm{mm} \mathrm{h}^{-1}$ give the snow precipitation rate change between the adjacent levels for the cross-section and event-mean snow precipitation rate. Precipitation rate changes in $\mathrm{mm} \mathrm{h}^{-1} \mathrm{~m}^{-1}$ give the snow precipitation rate change per elevation change of the cross-section and event-mean snow precipitation. The $\sim 95 \mathrm{~m}$ AGL used to distinguish between the different processes is given in bold.

\begin{tabular}{|c|c|c|c|c|c|c|c|}
\hline \multirow[b]{3}{*}{ Level } & \multirow[b]{3}{*}{ Elevation (m AGL) } & \multicolumn{2}{|c|}{ Wuosthorn } & \multirow{2}{*}{\multicolumn{2}{|c|}{$\begin{array}{c}\text { Schwarzhorn } \\
\text { Precipitation rate change }\end{array}$}} & \multirow{2}{*}{\multicolumn{2}{|c|}{$\frac{\text { Bocktenhorn }}{\text { Precipitation rate change }}$}} \\
\hline & & Precipit & rate change & & & & \\
\hline & & $\mathrm{mm} \mathrm{h}^{-1}$ & $\mathrm{~mm} \mathrm{~h}^{-1} \mathrm{~m}^{-1}$ & $\mathrm{~mm} \mathrm{~h}^{-1}$ & $\mathrm{~mm} \mathrm{~h}^{-1} \mathrm{~m}^{-1}$ & $\mathrm{~mm} \mathrm{~h}^{-1}$ & $\mathrm{~mm} \mathrm{~h}^{-1} \mathrm{~m}^{-1}$ \\
\hline 2 & $\sim 10$ & -0.001 & $-2.1 \times 10^{-4}$ & $-5.0 \times 10^{-5}$ & $-7.9 \times 10^{-6}$ & -0.0004 & $-6.7 \times 10^{-5}$ \\
\hline 3 & $\sim 19$ & -0.002 & $-2.2 \times 10^{-4}$ & 0.0002 & $2.4 \times 10^{-5}$ & -0.0007 & $-7.3 \times 10^{-5}$ \\
\hline 4 & $\sim 32$ & -0.004 & $-3.1 \times 10^{-4}$ & 0.0006 & $4.5 \times 10^{-5}$ & -0.001 & $-1.0 \times 10^{-4}$ \\
\hline 5 & $\sim 45$ & -0.004 & $-3.5 \times 10^{-4}$ & 0.001 & $9.5 \times 10^{-5}$ & -0.002 & $-1.2 \times 10^{-4}$ \\
\hline 6 & $\sim 58$ & -0.005 & $-3.5 \times 10^{-4}$ & 0.002 & $1.7 \times 10^{-4}$ & -0.001 & $-1.1 \times 10^{-4}$ \\
\hline 7 & $\sim 96$ & -0.005 & $-1.4 \times 10^{-4}$ & 0.006 & $1.6 \times 10^{-4}$ & -0.0006 & $-1.6 \times 10^{-5}$ \\
\hline 8 & $\sim 161$ & -0.009 & $-1.4 \times 10^{-4}$ & 0.019 & $3.0 \times 10^{-4}$ & 0.003 & $5.0 \times 10^{-5}$ \\
\hline 9 & $\sim 226$ & -0.0002 & $-3.0 \times 10^{-6}$ & 0.029 & $4.5 \times 10^{-4}$ & 0.013 & $2.0 \times 10^{-4}$ \\
\hline 10 & $\sim 291$ & 0.012 & $1.6 \times 10^{-4}$ & 0.037 & $-5.7 \times 10^{-4}$ & 0.020 & $3.1 \times 10^{-4}$ \\
\hline
\end{tabular}

ridge with respect to snow precipitation on the windward side of the mountain ridge by $26 \%-28 \%$.

\section{Conclusions}

In this study, we investigate near-surface predepositional precipitation processes shaping snow accumulation patterns in COSMO-WRF large-eddy simulations with a horizontal grid spacing of $50 \mathrm{~m}$. Additionally, the representation of terrain-flow-precipitation interactions is analyzed with respect to the model resolution.

The evaluation of different model resolutions reveals that near-surface processes are not resolved at a horizontal grid spacing of $450 \mathrm{~m}$. Horizontal grid spacings as high as $50 \mathrm{~m}$ are required to represent small-scale terrain-flow-precipitation interactions (i.e., local orographic precipitation enhancement and preferential deposition) shaping mountain-ridge-scale snow accumulation patterns, as flow separation on the leeward side of mountain ridges starts to be resolved at this resolution.
Smoothing of topography does not have a strong effect on the spatial variability of snow precipitation across mountain ridges.

Based on simulations with a horizontal grid spacing of $50 \mathrm{~m}$, the contribution of near-surface preferential deposition to snow deposition patterns is estimated to be on the order of $10 \%$, assuming that the contribution of cloud-dynamical precipitation formation in the lowest $\sim 95 \mathrm{~m}$ AGL is negligible. The combined effect of cloud-dynamical processes and mean advection may introduce a precipitation peak a few hundred meters downstream of the main ridge, enhancing precipitation by up to about $20 \%$. Overall, precipitation patterns show a strong temporal and spatial variability, which confirms that precipitation processes in the model are very dynamic. No clear relationship between wind speed and advection distance of precipitation is found. However, in our case studies of weaker effects of terrain-flow-precipitation interactions go along with a drier atmosphere.

TABLE A2. As in Table A1, but for the March event.

\begin{tabular}{|c|c|c|c|c|c|c|c|}
\hline \multirow[b]{3}{*}{ Level } & \multirow[b]{3}{*}{ Elevation (m AGL) } & \multicolumn{2}{|c|}{ Sattelhorn ridge } & \multirow{2}{*}{\multicolumn{2}{|c|}{$\frac{\text { Piz Radönt }}{\text { Precipitation rate change }}$}} & \multirow{2}{*}{\multicolumn{2}{|c|}{$\begin{array}{c}\text { Scaletta-Grialetsch } \\
\text { Precipitation rate change }\end{array}$}} \\
\hline & & Precipit & rate change & & & & \\
\hline & & $\mathrm{mm} \mathrm{h}^{-1}$ & $\mathrm{~mm} \mathrm{~h}^{-1} \mathrm{~m}^{-1}$ & $\mathrm{~mm} \mathrm{~h}^{-1}$ & $\mathrm{~mm} \mathrm{~h}^{-1} \mathrm{~m}^{-1}$ & $\mathrm{~mm} \mathrm{~h}^{-1}$ & $\mathrm{~mm} \mathrm{~h}^{-1} \mathrm{~m}^{-1}$ \\
\hline 2 & $\sim 9$ & -0.005 & $-7.3 \times 10^{-4}$ & -0.004 & $-6.1 \times 10^{-4}$ & $2.3 \times 10^{-4}$ & $3.7 \times 10^{-5}$ \\
\hline 3 & $\sim 18$ & -0.006 & $-6.9 \times 10^{-4}$ & -0.005 & $-5.7 \times 10^{-4}$ & $6.5 \times 10^{-4}$ & $7.0 \times 10^{-5}$ \\
\hline 4 & $\sim 31$ & -0.010 & $-8.3 \times 10^{-4}$ & -0.008 & $-6.7 \times 10^{-4}$ & 0.002 & $1.7 \times 10^{-4}$ \\
\hline 5 & $\sim 43$ & -0.011 & $-9.2 \times 10^{-4}$ & -0.009 & $-6.9 \times 10^{-4}$ & 0.003 & $2.6 \times 10^{-4}$ \\
\hline 6 & $\sim 56$ & -0.011 & $-9.0 \times 10^{-4}$ & -0.008 & $-6.5 \times 10^{-4}$ & 0.004 & $3.5 \times 10^{-4}$ \\
\hline 7 & $\sim 93$ & -0.017 & $-4.6 \times 10^{-4}$ & -0.011 & $-3.0 \times 10^{-4}$ & 0.007 & $1.8 \times 10^{-4}$ \\
\hline 8 & $\sim 156$ & -0.029 & $-4.7 \times 10^{-4}$ & -0.015 & $-2.3 \times 10^{-4}$ & 0.027 & $4.3 \times 10^{-4}$ \\
\hline 9 & $\sim 219$ & -0.030 & $-4.7 \times 10^{-4}$ & -0.006 & $-9.0 \times 10^{-5}$ & 0.032 & $5.1 \times 10^{-4}$ \\
\hline 10 & $\sim 282$ & -0.031 & $-4.9 \times 10^{-4}$ & 0.007 & $1.1 \times 10^{-4}$ & 0.030 & $4.7 \times 10^{-4}$ \\
\hline
\end{tabular}



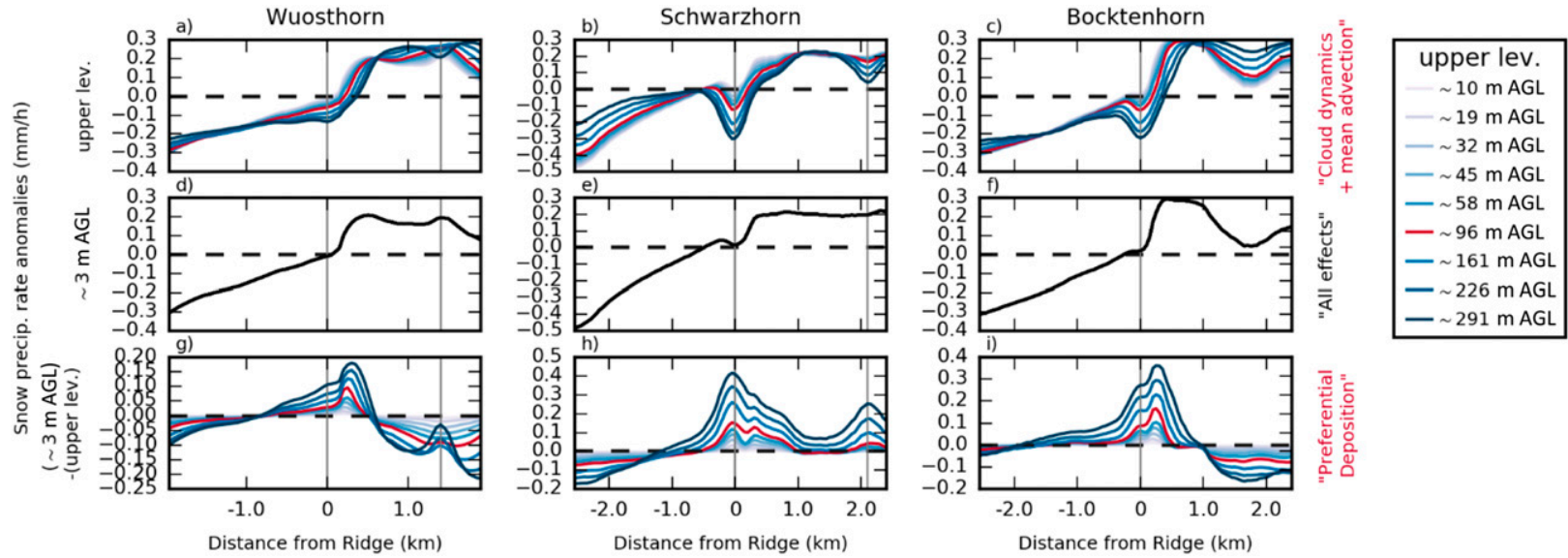

FIG. A1. Cross-section snow precipitation patterns across (left) Wuosthorn, (center) Schwarzhorn, and (right) Bocktenhorn (Fig. 1) for the January event (50-m horizontal grid spacing). (a)-(c) Event-mean snow precipitation rate anomalies at nine different model levels (upper lev.) between $\sim 10$ and $\sim 291 \mathrm{~m}$ AGL. The $\sim 96 \mathrm{~m}$ AGL is shown by the red line. (d)-(f) Event-mean snow precipitation rate anomalies at the lowest model level $\sim 3 \mathrm{~m} \mathrm{AGL}$. (g)-(i) Snow precipitation distribution due to processes between the upper level [shown in (a)-(c)] and the lowest model level $\sim 3 \mathrm{~m}$ AGL [shown in (d)-(f)]. Snow precipitation distribution due to processes in the lowest $\sim 96 \mathrm{~m}$ AGL is shown by the red line. Gray vertical lines mark the positions of the mountain ridges (i.e., relative elevation maxima of topography). Elevations of the upper level are the average elevation of the respective level across all three cross sections.

These analyses are based on a simple approach to distinguish particle-flow interactions and clouddynamical processes. No clear separation of the processes is possible based on conventional WRF Model output. As preferential deposition already starts at higher atmospheric levels than the lowest $\sim 95 \mathrm{~m}$ AGL as assumed in our study, the total contribution of preferential deposition is likely underestimated. On the other hand, the contribution of cloud dynamics is likely lower than our estimate of the combined effect, which includes local cloud dynamics and mean advection. Additionally, the model shows a tendency of overestimating orographic precipitation enhancement over the highest mountain peaks, which probably can be attributed to a not fully scale-independent behavior of the cloud microphysics model. A tracer experiment using a
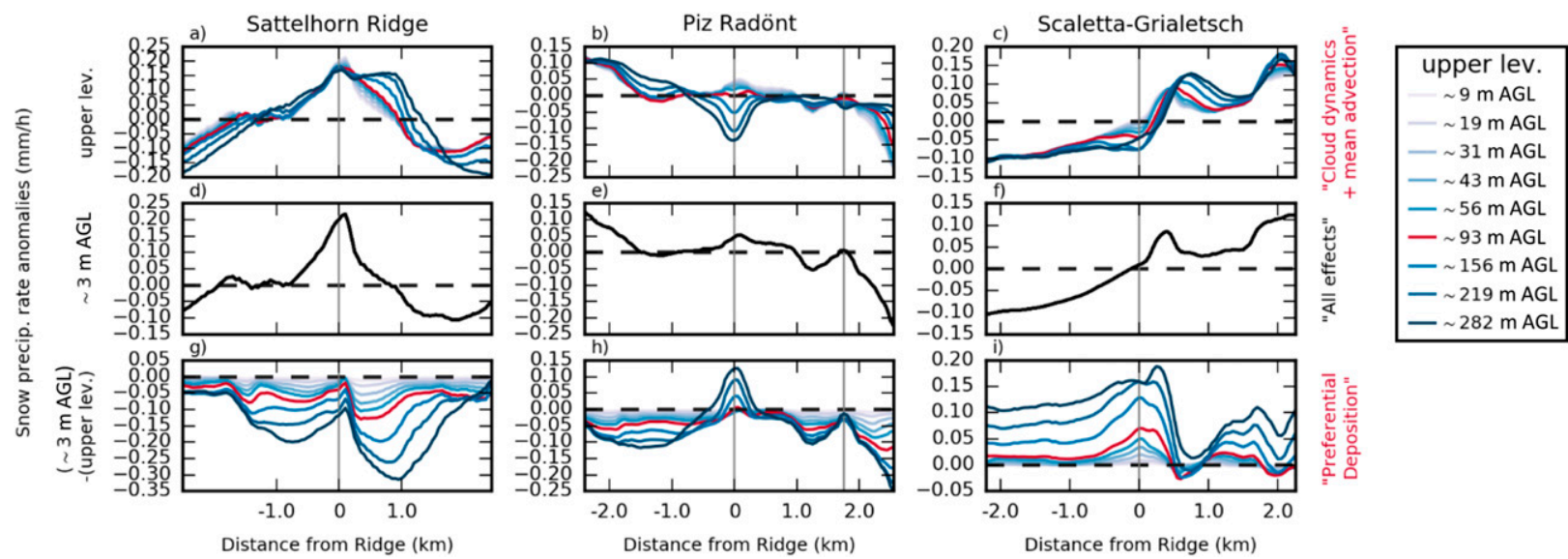

FIG. A2. Cross-section snow precipitation patterns across (left) Sattelhorn ridge, (center) Piz Radönt, and (right) the ridge between Scalettahorn and Piz Grialetsch (Fig. 1) for the March event (50-m horizontal grid spacing). (a)-(c) Event-mean snow precipitation rate anomalies at nine different model levels (upper lev.) between $\sim 9$ and $\sim 282 \mathrm{~m}$ AGL. The $\sim 93 \mathrm{~m}$ AGL is shown by the red line. (d)-(f) Event-mean snow precipitation rate anomalies at the lowest model level $\sim 3 \mathrm{~m}$ AGL. (g)-(i) Precipitation distribution due to processes between the upper level [shown in (a)-(c)] and the lowest model level $\sim 3 \mathrm{~m}$ AGL [shown in (d)-(f)]. Snow precipitation distribution due to processes in the lowest $\sim 92 \mathrm{~m} \mathrm{AGL}$ is shown by the red line. Gray vertical lines mark the positions of the mountain ridges (i.e., relative elevation maxima of topography). Elevations of the upper level are the average elevation of the respective level across all three cross sections. 

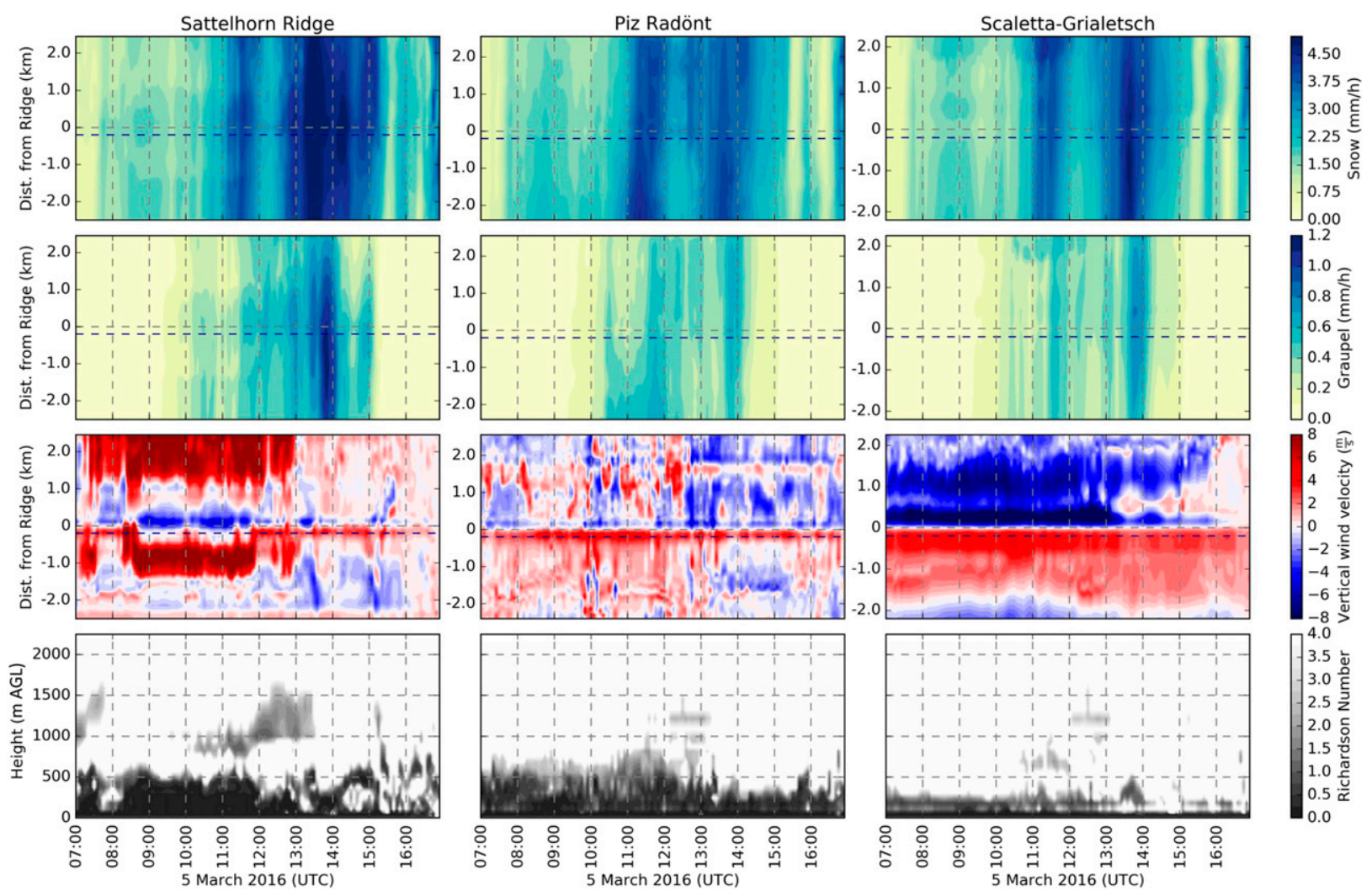

FIG. B1. Time-cross section diagrams of (first row) snow and (second row) graupel precipitation ( $\mathrm{mm} \mathrm{h}^{-1}$ ) and (third row) vertical wind velocity at $\sim 95 \mathrm{~m} \mathrm{AGL}\left(\mathrm{m} \mathrm{s}^{-1}\right)$ for the March event across (left) the Sattelhorn ridge, (center) Piz Radönt, and (right) the ridge between Scalettahorn and Piz Grialetsch. Horizontal gray dashed lines mark the mountain ridge. (fourth row) Richardson numbers $200 \mathrm{~m}$ upstream of the ridge (blue dashed line) are shown with respect to elevation above ground. All panels show 10-h mean values for simulations with a horizontal grid spacing of $50 \mathrm{~m}$.

passive tracer, which is transported with the flow could be valuable for a more rigorous distinction between particle-flow interactions and cloud-dynamical effects on precipitation patterns and should be conducted in the future. Furthermore, given that the model does not include postdepositional snow redistribution and is not coupled to an alpine surface processes model, we cannot address postdepositional snow redistribution, which has a strong impact on total snow accumulation variability (e.g., Vionnet et al. 2017).

Precipitation patterns as found in our COSMOWRF simulations resemble theoretical concepts of precipitation distribution due to predepositional precipitation processes (e.g., Lehning et al. 2008; Mott et al. 2014; CGSPL). Moreover, we could show that there is a certain agreement of filtered snow distribution from airborne photogrammetrically determined snow maps and modeled precipitation patterns for two transects in the Dischma valley. For two different transects, measured snow depth patterns show a closer agreement with precipitation patterns due to processes in the lowest $\sim 95 \mathrm{~m}$ AGL. This comparison is based on numerous assumptions and could be improved (i) by measurements of a single precipitation event and (ii) by including postdepositional snow redistribution in the modeling. Going toward higherresolution simulations, the development of a snow drift module for WRF or coupling WRF to an alpine surface processes model would facilitate a refined comparison.

For a precipitation event with high humidity, $26 \%-$ $28 \%$ snow accumulation enhancement on the leeward side of three mountain ridges with respect to the windward side of the mountain ridges is reported. Snow accumulation patterns were found to be very persistent for different winters and were found to be dominated by few major snowfall events (Schirmer et al. 2011). Given the interannual variability or even a shift in prevailing wind directions going along with climate change, future snow accumulation may look different with implications for local ecology, avalanche danger, and runoff formation (e.g., Brauchli et al. 2017). 

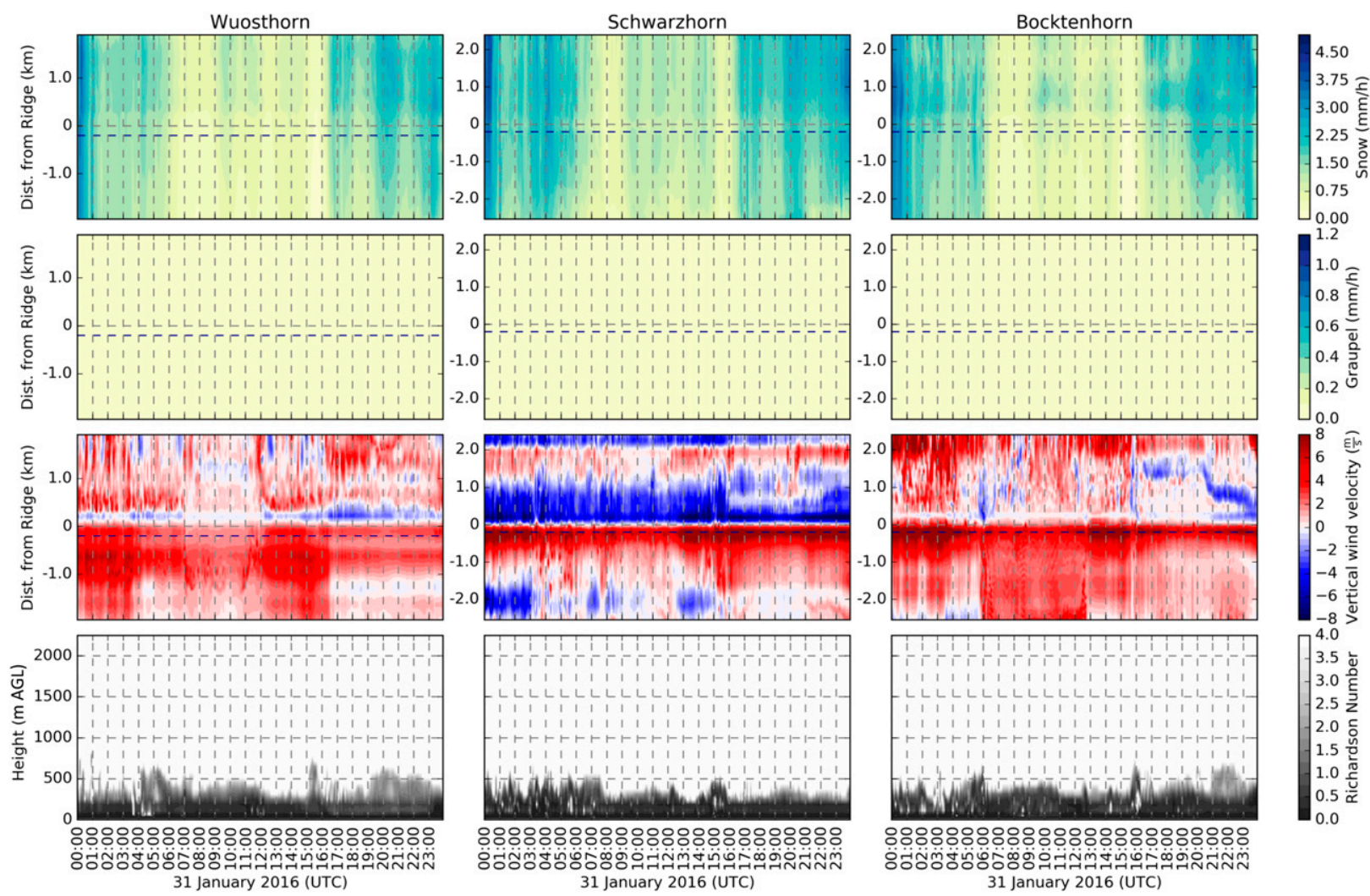

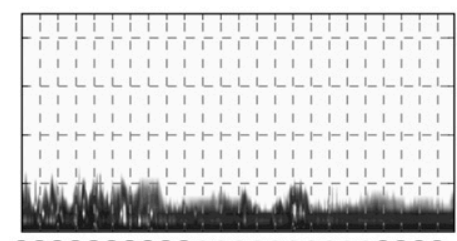

ঃ৪৪০০০০০০০০০০০০০০০০০০০০০

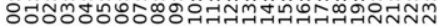
31 January 2016 (UTC)

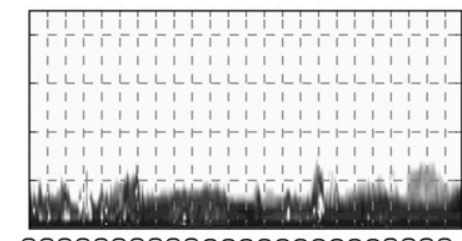

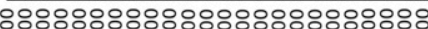

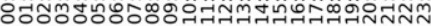
31 January 2016 (UTC)

FIG. B2. Time-cross section diagrams of (first row) snow and (second row) graupel precipitation ( $\mathrm{mm} \mathrm{h}^{-1}$ ) and (third row) vertical wind velocity at $\sim 95 \mathrm{~m} \mathrm{AGL}\left(\mathrm{m} \mathrm{s}^{-1}\right)$ for the January event for (left) Wuosthorn, (center) Schwarzhorn, and (right) Bocktenhorn. Horizontal gray dashed lines mark the mountain ridge. (fourth row) Richardson numbers $200 \mathrm{~m}$ upstream of the ridge (blue dashed line) are shown with respect to elevation above ground. All panels show 24-h mean values for simulations with a horizontal grid spacing of $50 \mathrm{~m}$.

Acknowledgments. This work is funded by the Swiss National Science Foundation (Project: Snow-atmosphere interactions driving snow accumulation and ablation in an Alpine catchment: The Dischma Experiment; SNF-Grant 200021_150146 and project: The sensitivity of very small glaciers to micro-meteorology; SNF-Grant P300P2_164644). We thank the Swiss Federal Office of Meteorology and Climatology (MeteoSwiss) for providing COSMO-2 analysis and for letting us use the regridding software fieldextra. Topographic data are reproduced by permission of swisstopo (JA100118). Special thanks go to Leica Geosystems for providing ADS80 data and to Yves Bühler and Mauro Marty for the processing of ADS80 data to obtain snow depth maps. Furthermore, we thank the Swiss National Supercomputing Center (CSCS) for supporting our project (Study on snow precipitation and accumulation over complex alpine terrain, s569) by providing computing time on their supercomputer and for technical assistance. For assistance with setting up COSMO-WRF, additional thanks go to Varun Sharma, Megan Daniels, and Louis Quéno. Additionally, we thank Heini Wernli and the anonymous reviewer for their questions, comments, and recommendations, which helped to improve the paper. Data presented in this article are published as Gerber et al. (2018b).

\section{APPENDIX A}

\section{Model Level Dependency and Precipitation Growth}

Tables A1 and A2 give summed event and crosssection mean precipitation growth between the nine lowest adjacent model levels. Figures A1 and A2 illustrate corresponding precipitation patterns across the six investigated mountain ridges for the January and March event, respectively. Patterns show a consistent change with increasing elevation above ground (increasing intensity of the blue color). The $\sim 95 \mathrm{~m}$ AGL (which is used for the analysis in the manuscript) is marked by a red line. 


\section{APPENDIX B}

\section{Stability Analysis}

The dry static stability is analyzed based on the BruntVäisälä frequency $N$ :

$$
N=\sqrt{\frac{g}{\theta} \frac{d \theta}{d z}}
$$

where $g$ is the acceleration of gravitation, $\theta$ is the potential temperature, and $z$ is the elevation. To analyze the dynamic stability the Richardson number ( $\mathrm{Ri}$ ) is calculated, which is buoyancy squared divided by the square of vertical shear of the horizontal velocity:

$$
\mathrm{Ri}=\frac{-g \frac{d \rho}{d z}}{\rho_{0}\left[\left(\frac{d u}{d z}\right)^{2}+\left(\frac{d v}{d z}\right)\right]},
$$

where $\rho$ is the air density and $\rho_{0}$ is the reference air density. Variables $u$ and $v$ are the west-east and southnorth components of horizontal wind velocity. Critical Richardson numbers for turbulence generation are between 0.2 and 1 , but turbulence may even be sustained at higher Richardson numbers (Galperin et al. 2007).

The static stability above all ridges and both simulations is about $N=0.01 \mathrm{~s}^{-1}$. Low Richardson numbers are sustained to higher elevations above ground for the March event (Fig. B1) compared to the January event, for which low Richardson numbers are restricted to the lowest $500 \mathrm{~m}$ of the atmosphere (Fig. B2).

\section{REFERENCES}

Banta, R. M., 1990: The role of mountain flows in making clouds. Atmospheric Processes over Complex Terrain, Meteor. Monogr., No. 45, Amer. Meteor. Soc., 229-283, https://doi.org.10.1007/ 978-1-935704-25-6_9.

Beljaars, A. C. M., 1995: The parameterization of surface fluxes in large-scale models under free convection. Quart. J. Roy. Meteor. Soc., 121, 255-270, https://doi.org/10.1002/qj.49712152203.

Bergeron, T., 1965: On the low-level redistribution of atmospheric water caused by orography. Proc. Int. Cloud Physics, Tokyo, Japan, Amer. Meteor. Soc., 96-100.

Bernhardt, M., K. Schulz, G. Liston, and G. Zängl, 2012: The influence of lateral snow redistribution processes on snow melt and sublimation in alpine regions. J. Hydrol., 424-425, 196206, https://doi.org/10.1016/j.jhydrol.2012.01.001.

Brauchli, T., E. Trujillo, H. Huwald, and M. Lehning, 2017: Influence of slope-scale snowmelt on catchment response simulated with the Alpine3d model. Water Resour. Res., 53, 10 723-10739, https://doi.org/10.1002/2017WR021278.

Bühler, Y., M. Marty, L. Egli, J. Veitinger, T. Jonas, P. Thee, and C. Ginzler, 2015: Snow depth mapping in high-alpine catchments using digital photogrammetry. Cryosphere, 9, 229-243, https://doi.org/10.5194/tc-9-229-2015.
Carruthers, D. J., and J. C. R. Hunt, 1990: Fluid mechanics of airflow over hills: Turbulence, fluxes, and waves in the boundary layer. Atmospheric Processes over Complex Terrain, Meteor. Monogr., No. 45, Amer. Meteor. Soc., 83-107, https://doi.org/10.1007/9781-935704-25-6_5.

De Wekker, S. F. J., 2002: Structure and morphology of the convective boundary layer in mountainous terrain. Ph.D. thesis, Dept. of Earth and Ocean Sciences, University of British Colombia, 191 pp., https://doi.org/10.14288/1.0052567.

Dyer, A. J., and B. B. Hicks, 1970: Flux-gradient relationships in the constant flux layer. Quart. J. Roy. Meteor. Soc., 96, 715721, https://doi.org/10.1002/qj.49709641012.

Galperin, B., S. Sukoriansky, and P. S. Anderson, 2007: On the critical Richardson number in stably stratified turbulence. Atmos. Sci. Lett., 8, 65-69, https://doi.org/10.1002/asl.153.

Gerber, F., and V. Sharma, 2018: Running COSMO-WRF on very high resolution over complex terrain. Laboratory of Cryospheric Sciences, École Polytechnique Fédérale de Lausanne, https://doi.org/10.16904/envidat.35.

, M. Lehning, S. W. Hoch, and R. Mott, 2017: A close-ridge small-scale atmospheric flow field and its influence on snow accumulation. J. Geophys. Res. Atmos., 122, 7737-7754, https://doi.org/10.1002/2016JD026258.

— cipitation and accumulation in COSMO-WRF simulations and radar estimations over complex terrain. Cryosphere, 12, 3137-3160, https://doi.org/10.5194/tc-12-3137-2018.

, V. Sharma, R. Mott, M. Daniels, and M. Lehning, 2018b: DISCHMEX - High-resolution WRF simulations in complex alpine terrain and station measurements. Laboratory of Cryospheric Sciences, School of Architecture and Civil Engineering, École Polytechnique Fédérale de Lausanne, accessed 25 Jan 2019, https://doi.org/10.16904/envidat.50.

Grazioli, J., G. Lloyd, L. Panziera, C. R. Hoyle, P. J. Connolly, J. Henneberger, and A. Berne, 2015: Polarimetric radar and in situ observations of riming and snowfall microphysics during CLACE 2014. Atmos. Chem. Phys., 15, 13 787-13 802, https://doi.org/10.5194/acp-15-13787-2015.

Grünewald, T., and Coauthors, 2013: Statistical modelling of the snow depth distribution in open alpine terrain. Hydrol. Earth Syst. Sci., 17, 3005-3021, https://doi.org/10.5194/hess-17-30052013.

- Y. Bühler, and M. Lehning, 2014: Elevation dependency of mountain snow depth. Cryosphere, 8, 2381-2394, https:// doi.org/10.5194/tc-8-2381-2014.

Hogan, R. J., P. R. Field, A. J. Illingworth, R. J. Cotton, and T. W. Choularton, 2002: Properties of embedded convection in warm-frontal mixed-phase cloud from aircraft and polarimetric radar. Quart. J. Roy. Meteor. Soc., 128, 451-476, https:// doi.org/10.1256/003590002321042054.

Hong, S.-Y., Y. Noh, and J. Dudhia, 2006: A new diffusion package with an explicit treatment of entrainment processes. Mon. Wea. Rev., 134, 2318-2341, https://doi.org/10.1175/MWR3199.1.

Kirchner, P. B., R. C. Bales, N. P. Molotch, J. Flanagan, and Q. Guo, 2014: Lidar measurement of seasonal snow accumulation along an elevation gradient in the southern Sierra Nevada, California. Hydrol. Earth Syst. Sci., 18, 4261-4275, https://doi.org/10.5194/hess-18-4261-2014.

Lehning, M., and R. Mott, 2016: Bodennahe atmosphärische Prozesse und ihre Wirkung auf die hochalpine Schneedecke. Promet Meteor. Fortbild., 98, 59-67.

— H. Löwe, M. Ryser, and N. Raderschall, 2008: Inhomogeneous precipitation distribution and snow transport in steep terrain. 
Water Resour. Res., 44, W07404, https://doi.org/10.1029/ 2007WR006545.

Morrison, H., J. A. Curry, and V. I. Khvorostyanov, 2005: A new double-moment microphysics parameterization for application in cloud and climate models. Part I: Description. J. Atmos. Sci., 62, 1665-1677, https://doi.org/ 10.1175/JAS3446.1.

— G. Thompson, and V. Tatarskii, 2009: Impact of cloud microphysics on the development of trailing stratiform precipitation in a simulated squall line: Comparison of one- and two-moment schemes. Mon. Wea. Rev., 137, 991-1007, https://doi.org/10.1175/ 2008MWR2556.1.

Mott, R., and M. Lehning, 2010: Meteorological modeling of very high-resolution wind fields and snow deposition for mountains. J. Hydrometeor., 11, 934-949, https://doi.org/10.1175/ 2010JHM1216.1.

, M. Schirmer, M. Bavay, T. Grünewald, and M. Lehning, 2010: Understanding snow-transport processes shaping the mountain snow-cover. Cryosphere, 4, 545-559, https://doi.org/10.5194/ tc-4-545-2010.

- D. Scipión, M. Schneebeli, N. Dawes, A. Berne, and M. Lehning, 2014: Orographic effects on snow deposition patterns in mountainous terrain. J. Geophys. Res. Atmos., 119, 1363-1385, https://doi.org/10.1002/2013JD019880.

—, S. Schlögl, L. Dirks, and M. Lehning, 2017: Impact of extreme land surface heterogeneity on micrometeorology over spring snow cover. J. Hydrometeor., 18, 2705-2722, https://doi.org/ 10.1175/JHM-D-17-0074.1.

Niu, G.-Y., and Coauthors, 2011: The community Noah land surface model with multiparameterization options (Noah-MP): 1 . Model description and evaluation with local-scale measurements. J. Geophys. Res., 116, D12109, https://doi.org/10.1029/ 2010JD015139.

Paulson, C. A., 1970: The mathematical representation of wind speed and temperature profiles in the unstable atmospheric surface layer. J. Appl. Meteor., 9, 857-861, https://doi.org/ 10.1175/1520-0450(1970)009<0857:TMROWS >2.0.CO;2.

Pontoppidan, M., J. Reuder, S. Mayer, and E. W. Kolstad, 2017: Downscaling an intense precipitation event in complex terrain: The importance of high grid resolution. Tellus, $69 \mathbf{A}$, 1271561, https://doi.org/10.1080/16000870.2016.1271561.

Rasmussen, R., and Coauthors, 2011: High-resolution coupled climate runoff simulations of seasonal snowfall over Colorado: A process study of current and warmer climate. J. Climate, 24, 3015-3048, https://doi.org/10.1175/2010JCLI3985.1.

Reisner, J., R. M. Rasmussen, and R. T. Bruintjes, 1998: Explicit forecasting of supercooled liquid water in winter storms using the MM5 mesoscale model. Quart. J. Roy. Meteor. Soc., 124, 1071-1107, https://doi.org/10.1002/qj.49712454804.

Richard, E., A. Buzzi, and G. Zängl, 2007: Quantitative precipitation forecasting in the Alps: The advances achieved by the Mesoscale Alpine Programme. Quart. J. Roy. Meteor. Soc., 133, 831-846, https://doi.org/10.1002/qj.65.

Roth, A., R. Hock, T. V. Schuler, P. A. Bieniek, M. Pelto, and A. Aschwanden, 2018: Modeling winter precipitation over the Juneau icefield, Alaska, using a linear model of orographic precipitation. Front. Earth Sci., 6, 20, https://doi.org/10.3389/ feart.2018.00020.

Schirmer, M., V. Wirz, A. Clifton, and M. Lehning, 2011: Persistence in intra-annual snow depth distribution: 1. Measurements and topographic control. Water Resour. Res., 47, W09516, https:// doi.org/10.1029/2010WR009426.

Schlögl, S., M. Lehning, and R. Mott, 2018: Representation of horizontal transport processes in snowmelt modelling by applying a footprint approach. Front. Earth Sci., 6, 120, https:// doi.org/10.3389/feart.2018.00120.

Skamarock, W. C., and Coauthors, 2008: A description of the Advanced Research WRF version 3. NCAR Tech. Note NCAR/ TN-475+STR, 113 pp., https://doi.org/10.5065/D68S4MVH.

Smith, R., and I. Barstad, 2004: A linear theory of orographic precipitation. J. Atmos. Sci., 61, 1377-1391, https://doi.org/ 10.1175/1520-0469(2004)061<1377:ALTOOP>2.0.CO;2.

Sommer, C. G., M. Lehning, and R. Mott, 2015: Snow in a very steep rock face: Accumulation and redistribution during and after a snowfall event. Front. Earth Sci., 3, 73, https://doi.org/ 10.3389/feart.2015.00073.

Stoelinga, M. T., R. E. Stewart, G. Thompson, and J. M. Thériault, 2013: Microphysical processes within winter orographic cloud and precipitation systems. Mountain Weather Research and Forecasting: Recent Progress and Current Challenges, F. K. Chow, S. F. J. De Wekker, and B. J. Snyder, Eds., Springer, 345-408, https://doi.org/10.1007/978-94-007-4098-3_7.

Vionnet, V., E. Martin, V. Masson, C. Lac, F. Naaim Bouvet, and G. Guyomarc'h, 2017: High-resolution large eddy simulation of snow accumulation in alpine terrain. J. Geophys. Res. Atmos., 122, 11 005-11 021, https://doi.org/10.1002/2017JD026947.

Vögeli, C., M. Lehning, N. Wever, and M. Bavay, 2016: Scaling precipitation input to spatially distributed hydrological models by measured snow distribution. Front. Earth Sci., $\mathbf{4}$, 108, https://doi.org/10.3389/feart.2016.00108.

Wang, Z., and N. Huang, 2017: Numerical simulation of the falling snow deposition over complex terrain. J. Geophys. Res. Atmos., 122, 980-1000, https://doi.org/10.1002/2016JD025316.

Webb, E. K., 1970: Profile relationships: The log-linear range, and extension to strong stability. Quart. J. Roy. Meteor. Soc., 96, 67-90, https://doi.org/10.1002/qj.49709640708.

Yang, Z.-L., and Coauthors, 2011: The community Noah land surface model with multiparameterization options (Noah-MP): 2. Evaluation over global river basins. J. Geophys. Res., 116, D12110, https://doi.org/10.1029/2010JD015140.

Zängl, G., 2007: Small-scale variability of orographic precipitation in the Alps: Case studies and semi-idealized numerical simulations. Quart. J. Roy. Meteor. Soc., 133, 1701-1716, https://doi.org/10.1002/qj.163.

Zhang, D.-L., and R. A. Anthes, 1982: A high-resolution model of the planetary boundary layer-Sensitivity tests and comparisons with SESAME-79 data. J. Appl. Meteor., 21, 1594-1609, https://doi.org/10.1175/1520-0450(1982) 021<1594:AHRMOT>2.0.CO;2. 